Running head: EXTRAVERSION PREDICTS REWARD SENSITIVITY

Extraversion but not Depression Predicts Reward Sensitivity:

Revisiting the Measurement of Anhedonic Phenotypes

Submitted: 6/xx/2020 


\begin{abstract}
Recently, increasing efforts have been made to define and measure dimensional phenotypes associated with psychiatric disorders. One example is a probabilistic reward task developed by Pizzagalli et al. (2005) to assess anhedonia, by measuring participants' responses to a differential reinforcement schedule. This task has been used in many studies, which have connected blunted reward response in the task to depressive symptoms, across clinical groups and in the general population. The current study attempted to replicate these findings in a large community sample and also investigated possible associations with Extraversion, a personality trait linked theoretically and empirically to reward sensitivity. Participants $(N=299)$ completed the probabilistic reward task, as well as the Beck Depression Inventory, Personality Inventory for the DSM-5, Big Five Inventory, and Big Five Aspect Scales. Our direct replication attempts used bivariate analyses of observed variables and ANOVA models. Follow-up and extension analyses used structural equation models to assess relations among latent reward sensitivity, depression, Extraversion, and Neuroticism. No significant associations were found between reward sensitivity (i.e., response bias) and depression, thus failing to replicate previous findings. Reward sensitivity (both modeled as response bias aggregated across blocks and as response bias controlling for baseline) showed positive associations with Extraversion, but not Neuroticism. Findings suggest reward sensitivity as measured by this probabilistic reward task may be related primarily to Extraversion and its pathological manifestations, rather than to depression per se, consistent with existing models that conceptualize depressive symptoms as combining features of Neuroticism and low Extraversion. Findings are discussed in broader contexts of dimensional psychopathology frameworks, replicable science, and behavioral task reliability.
\end{abstract}

Key Words: Reward, Extraversion, Personality, Anhedonia, Replication 


\section{Extraversion but not Depression Predicts Reward Sensitivity: Revisiting the Measurement of Anhedonic Phenotypes}

A longstanding debate exists regarding the utility of categorical versus dimensional frameworks for identifying and classifying psychopathology. Historically, the majority of research in psychiatry and clinical psychology has been framed around the categorical diagnoses set forth by the Diagnostic and Statistical Manual of Mental Disorders (DSM). Despite their influence and popularity, traditional DSM diagnoses have pervasive problems, including heterogeneity within and overlap among diagnostic categories, and much empirical research indicates that continuous, dimensional methods of psychopathology are more reliable and valid than traditional frameworks (Kotov et al., 2017; Markon, Chmielewski, \& Miller, 2011; Wright et al., 2013).

In the case of depressive disorders, the problems with categorical diagnoses are evident in their high degree of comorbidity with other diagnoses (e.g., anxiety disorders) and the heterogeneity of symptoms used as criteria for diagnosis, which include contrasting symptoms such as hypersomnia and insomnia, or overeating and lack of appetite (Fried, 2017; Hasler et al., 2004; Hyman, 2002). These problems pose challenges not only in the clinic, where they raise barriers for using diagnosis to guide effective treatment, but also in research that attempts to clarify the psychological and biological mechanisms underlying psychiatric disorders. In response to these challenges, continuous, dimensional frameworks account for comorbidity and heterogeneity by using psychopathology-related traits and symptom dimensions that cut across diagnostic categories and are organized hierarchically (e.g., Krueger \& Markon, 2014; Kotov et al., 2017). Narrower dimensions at lower levels account for heterogeneity, and they are grouped at higher levels according to their empirical patterns of covariance, which allows for the modeling of comorbidity. 
In addition to focusing on transdiagnostic trait and symptom dimensions, another important approach to improving research on psychopathology is identifying and quantifying specific transdiagnostic affective and cognitive mechanisms that might contribute to downstream behavioral dysfunction and clinical symptomatology. This approach is exemplified by the National Institute of Mental Health's Research Domain Criteria (RDoC), which identifies transdiagnostic features of psychopathology at multiple levels of analysis, focusing on the use of behavioral paradigms and investigation of neural circuits (Insel et al., 2010). One example of an important transdiagnostic phenotype that has been researched both as a continuous trait or symptom dimension and in terms of underlying mechanisms is anhedonia, which is related to depression and a variety of other traditional clinical diagnoses. Anhedonia can be defined as a relative failure to obtain pleasure from activities, or stimuli, previously experienced as rewarding (Keedwell et al., 2005). Anhedonia has been demonstrated as a vulnerability factor for depressive symptomatology (Loas, 1996; Meehl, 1975) and is elevated among individuals diagnosed with depressive disorders (Snaith, 1993). Various attempts have been made to operationalize anhedonia, including tasks that assess responsiveness to rewarding stimuli (Costello, 1972) and numerous self-report measures, including subscales derived from the Beck Depression Inventory (BDI; Beck et al., 1961; Beck et al., 1996; Joiner et al., 2003; Pizzagalli et al., 2005). Further, anhedonia has been conceptualized as part of a broader framework of dimensional psychopathology, as measured by instruments such as the Personality Inventory for the DSM-5 (PID-5; Krueger et al., 2012). In addition to being a key feature of depressive disorders, anhedonia is also present in other DSM diagnoses, from bipolar disorder and schizophrenia to various personality disorders (Andreasen et al., 2012; Di Nicola, 2013; Kwapil \& Barrantes-Vidal, 2015).

One task developed to operationalize and measure anhedonia is a probabilistic reward task, introduced by Tripp and Alsop (1999) and popularized by Pizzagalli et al. (2005). This task has been 
referred to both as the Probabilistic Reward Task (PRT; Pizzagalli et al., 2008a, Pizzagalli et al., 2008b) and the Implicit Probabilistic Incentive Learning Task (IPILT; Barch et al., 2017); throughout the rest of this paper, we will use the acronym PRT to refer to the task. In the PRT, participants are rewarded at a differential frequency for discriminating between long and short mouth stimuli presented on a cartoon face, resulting in a systematic (but not typically conscious) preference for one stimulus over the other. Participants' response bias toward the more frequently rewarded or "rich" stimulus is an index of reward sensitivity, and participants' change in response bias from the beginning to the middle of the PRT is often used as an index of reward learning. Change in response bias was found to correlate negatively with scores on the BDI in an undergraduate convenience sample $(N=61)$ and to differ significantly in that sample between individuals with BDI scores high enough to indicate "mild depression" $(\geq 16, N=15)$ and those with low scores $(0-6, N=21)$ (Pizzagalli et al., 2005). In another study, individuals diagnosed with depressive disorders demonstrated lower reward responsiveness than healthy controls (Pizzagalli et al., 2008), and first-degree relatives of those with major depression also show lower reward responsiveness (Liu et al., 2015). PRT performance has also been found to predict perceived stress (Pizzagalli et al., 2007) and performance responds to acute stress (Bogdan et al., 2006). Other research has highlighted associations between performance on the PRT and relevant brain systems, such as resting electrical activity in the orbitofrontal cortex (Webb et al., 2016), feedbackrelated electrical potentials (Bogdan et al., 2011; Bress \& Hajcak, 2013; Whitton et al., 2016), rewardrelated response in the anterior cingulate and basal ganglia (Santesso et al., 2008; Whitton et al., 2016), and dopaminergic functioning (Kaiser et al., 2018; Santesso et al., 2009).

Despite the breadth and apparent consistency of findings, many studies using the PRT have had serious statistical limitations such as small sample sizes and use of dichotomized scores (e.g., Pizzagalli et al., 2005; 2008), both of which reduce statistical power and thus increase the proportion of 
significant results that are false positives (Cohen, 1983; MacCallum et al., 2002). Furthermore, one of the highest-powered studies published using the PRT failed to show an effect of depression on response bias, comparing patients with major depressive disorder to healthy controls $(N=294$; Lawlor et al., 2019) and other recent data fails to support a correlation between response bias and measures of depression, anhedonia, and Neuroticism—a personality trait related to depression $(N=216$; Webb et al., 2020). The current study attempted to replicate the correlation between BDI scores and reward sensitivity, reported by Pizzagalliet al. (2005), and to examine potential associations with another personality trait related to depression-low Extraversion (Allen et al., 2017; Kotov et al., 2010). We used a large sample with adequate power to detect correlations in the expected range of effect sizes and to estimate such correlations with reasonable precision (Gignac \& Szoderai, 2016; Hemphill, 2003; Richard et al., 2003; Schönbrodt \& Perugini, 2013).

In addition to attempting a direct replication of the association between reward sensitivity and depression, we also decided to extend our analyses to consider the likely association of reward sensitivity with relevant personality variables, namely Extraversion and its pathological variants. Research on dimensional approaches to psychopathology suggests that psychiatric symptoms can be described as pathological variants of behaviors described by normal personality variation (DeYoung \& Krueger, 2018). Most major dimensions of risk for psychopathology appear to reflect the same latent variables as the major dimensions of personality. For instance, pathological low Extraversion has been labeled "Detachment." Detachment is a core feature of depressive disorders and is also largely analogous to the negative symptoms of schizophrenia and negative schizotypy (Kotov et al., 2016; Kotov et al., 2017).

Depression has been shown to be related to both low Extraversion and high Neuroticism (Allen et al., 2017; Kotov et al., 2010). This combination of low Extraversion and high Neuroticism is 
reflected in the item content of various self-report measures of depression, particularly heterogeneous scales such as the BDI. Neuroticism is strongly related to depression and most other forms of psychopathology (Widiger, 2011), and the negative affect and sensitivity to punishment characterizing Neuroticism is a key component of depression. Nonetheless, depression is also related to lack of reward responsiveness, reduced positive emotionality, and social withdrawal, all of which are components of low Extraversion (DeYoung, 2015; Lucas et al., 2000). Though Extraversion is often considered colloquially as primarily related to sociability, a large body of evidence suggests that the defining characteristic of Extraversion is reward sensitivity generally, not mere sociability, such that extraverts typically have more energy and positive affect than introverts even in nonsocial situations (Corr, 2008; Gray \& McNaughton, 2000; Lucas et al., 2000; Smillie et al., 2007; Smillie, 2008; Smillie et al., 2011a; Smillie et al., 2011b; Smillie et al., 2012; Smillie, 2013). Thus, measures of Extraversion may show stronger effects than measures of depression when assessing relations with reward sensitivity, anhedonia, and other related variables. In other words, to the extent that depression is associated with reduced reward sensitivity, we hypothesize that this is because depression involves low Extraversion, which is, in theory, the primary manifestation in personality of variation in reward sensitivity.

The current study attempted to replicate findings from an investigation of the association between depression and reward sensitivity in a nonclinical population, while also conducting follow-up and extension analyses testing a more complete model of depression, Extraversion, Neuroticism, and reward sensitivity. The specific findings of Pizzagalli et al. (2005) that we attempted to replicate include (1) that reward learning was evident in the PRT for the sample as a whole, (2) the significant difference in response bias between participants meeting the threshold for "mild depression" in their BDI scores and those with low BDI scores, (3) the significant correlation between a measure of Melancholic depression derived from the BDI and changes in response bias from Block 1 to 3 of the 
PRT, and (4) the significant difference in Melancholic depression scores between subjects with negative and positive changes in response bias (Pizzagalli et al., 2005).

First, we hypothesized that we would replicate the results of Pizzagalli et al. (2005), in that participants would show a reward-learning effect and depression would be negatively associated with response bias across all blocks of the PRT and with response bias later in the PRT, relative to baseline. We also attempted a conceptual replication of Pizzagalli's depression findings by examining additional measures of Depressivity and Anhedonia from the PID-5. Second, we hypothesized that response bias and response bias relative to baseline would be positively related to Extraversion; we anticipated these effects would be stronger than those for depression, which reflects a combination of Detachment (low Extraversion) and Neuroticism. Consequently, our final hypothesis was that the effects of Extraversion and associated variance in depression on response bias would be more apparent when controlling for variance in Neuroticism.

\section{Method}

\section{Participants}

A total of 333 participants completed the PRT. Exclusion criteria based on performance were identical to those used by Pizzagalli et al. (2005). Thirty participants were excluded from further analyses because of a high prevalence of reaction time outliers (a total of more than 40 outliers across the task, with outliers being identified as individual trials with a reaction time that did not fall within a range of $\pm 3 \mathrm{SD}$ of a given participant's mean reaction time). Four additional participants were excluded from the analyses for having below-chance accuracy. Our final sample consisted of 299 people (148 females) between the ages of 20 and $41(M=26.37, S D=5.12)$. Participants were recruited from the community surrounding [LOCATION BLINDED], primarily through online advertisements, and individuals represented a variety of professions, with relatively few students. All participants 
completed informed consent and all protocols were approved by the [INSTITUTION NAME BLINDED] Institutional Review Board.

\section{Probabilistic Reward Task (PRT)}

Task Description. The PRT is a 25-minute signal detection task that has been validated in multiple previous studies and was designed to assess individuals' implicit responsiveness to monetary reinforcements (Bogdan \& Pizzagalli, 2006; Pizzagalli et al., 2005; 2008). For each trial, participants were presented with a fixation cross for $500 \mathrm{~ms}$, followed by a mouthless cartoon face. Then, either a long $(13 \mathrm{~mm})$ or short $(11.5 \mathrm{~mm})$ mouth was presented on the face, for $100 \mathrm{~ms}$. For each trial, participants were asked to determine whether the mouth presented was short or long. The cartoon face was then presented without the mouth, until the participant used the keyboard to make a response. The long and short mouths were presented equally as often, in a random order, with no more than three sequential presentations of a given mouth stimulus. A total of 300 trials were presented, split into three blocks of 100 trials (hereafter referred to as Block 1 for the first 100 trials and Blocks 2 and 3 for the following sets of 100 trials). A random selection of correct responses received positive feedback, for each of which participants were rewarded with 5 cents. Feedback was always accompanied by the monetary reward and no negative feedback was given. Figure 1 illustrates the PRT stimuli and procedure.

Figure 1. PRT stimuli and procedure

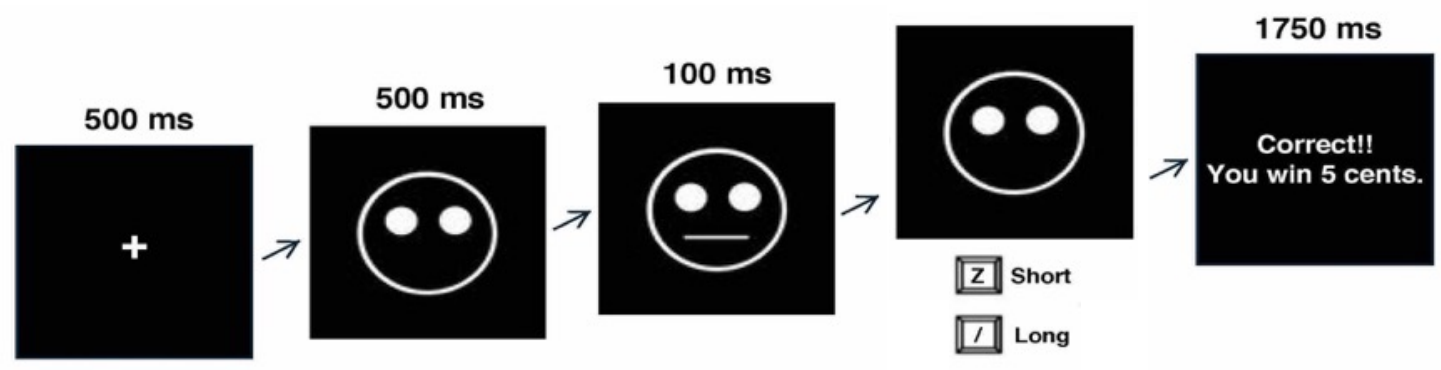


Across all three blocks of the PRT, an asymmetrical reinforcer ratio was used to encourage a response bias toward one of the two mouth stimuli (McCarthy \& Davison, 1979; Tripp \& Alsop, 1999). Correct identification of the long mouth (rich stimulus) was rewarded three times as often, compared to the short mouth (lean stimulus). In the current study, the long mouth was always rewarded more. In each block, a total of 40 trials received reward feedback, 30 trials for the rich stimulus (long mouth) and 10 trials for the lean stimulus (short mouth). Prior to the administration of the PRT, participants were told to win as much money as possible and that they would not be rewarded for every correct response they made. However, they were not told that there would be a disproportionate ratio of rewards between the two stimuli. The participants' performances were analyzed with respect to their accuracy, discriminability, and degree of response bias formed throughout the PRT.

Some previous research (albeit limited in scope and statistical power) has demonstrated the reliability of the PRT. Split-half reliability calculated using the Spearman-Brown prophecy formula for even and odd trials on the task has been reported at a coefficient of 0.71 , in a sample of 294 individuals, demonstrating acceptable internal consistency (Lawlor et al., 2019). Test-retest reliability (i.e., the correction between participants' performance scores at two different time points, such as test sessions that are a month apart), however, has only been evaluated in very small samples, showing testretest correlations for response bias of $\mathrm{r}=.57(\mathrm{~N}=25$; Pizzagalli et al., 2005) and $\mathrm{r}=.62(\mathrm{~N}=16$; Santesso et al., 2008).

Data Collection and Reduction. Primary variables of interest for the PRT included accuracy, discriminability, response bias, and change in response bias. Accuracy was calculated as the percentage of stimuli correctly labeled as long or short for each of the three blocks. Discriminability— $\log (\mathrm{d})$ - and response bias — $\log (\mathrm{b})$ — variables were calculated using signal detection principles (McCarthy \& Davison, 1979; Tripp \& Alsop, 1999). Discriminability represents participants' tendency to correctly 
distinguish between stimuli after controlling for bias, whereas response bias represents a tendency to select one stimulus over the other (Pizzagalli et al., 2005). ${ }^{1}$

$$
\begin{aligned}
& \log (d)=\frac{1}{2} \log \left(\frac{\text { Long }_{\text {correct }} \times \text { Short }_{\text {correct }}}{\text { Long }_{\text {incorrect }} \times \text { Short }_{\text {incorrect }}}\right) \\
& \log (b)=\frac{1}{2} \log \left(\frac{\text { Long }_{\text {correct }} \times \text { Short }_{\text {incorrect }}}{\text { Long }_{\text {incorrect }} \times \text { Short }_{\text {correct }}}\right)
\end{aligned}
$$

Discriminability and response-bias variables were calculated for each block, after which, main variables for discriminability and response bias were calculated by averaging values from Blocks 2 and 3, given that Block 1 was considered a primary learning phase. Finally, two change-in-response-bias variables were calculated as the difference in participants' response bias from Block 1 to Block 2 and from Block 1 to Block 3.

Importantly, when using the performance measures derived from PRT, there are three primary ways to operationalize reward sensitivity: 1) response bias throughout all three blocks of the task, 2) difference scores for response bias from Block 1 to Blocks 2 or 3, and 3) response bias in Blocks 2 and 3 of the task, controlling for Block 1 response bias (i.e., baseline). As response bias in the PRT is a measure of how differential reward frequencies influence participants' tendency to select one stimulus over the other, levels of response bias throughout the PRT can be interpreted as an index of reward sensitivity (i.e., participants with a greater tendency to select the more-rewarded stimulus have a higher response bias, which is interpreted as higher reward sensitivity). In addition to showing greater bias

\footnotetext{
${ }^{1}$ As is standard when using log transformations - because logarithmic functions are undefined for values of zero- $-\mathrm{a}$ constant of .5 was added to all variables before they were entered into the $\log (\mathrm{d})$ and $\log (\mathrm{b})$ formulas (Brown \& White, 2005). It is also worth noting that our formulas differ slightly from the traditional signal detection measures of d' and c (Green \& Swets, 1966; Stanislaw \& Todorov, 1999), as they use logit transformations rather than inverse normal transformations (McCarthy \& Davison, 1979); values obtained, however, yield similar results and are related almost linearly (Brown \& White, 2005; Brown \& White, 2009). The current formulas were used to facilitate consistency with previous research using the PRT (Pizzagalli et al., 2005; Tripp \& Alsop, 1999).
} 
throughout the entire task, we expect individuals more sensitive to reward cues to develop a greater response bias from the beginning to the end of the task (i.e., show greater levels of reward learning). This reward learning effect is another way to define reward sensitivity in the PRT and can be operationalized using either difference scores (differences in response bias from Block 1 to Block 2 or 3) or by controlling for bias in Block 1 when predicting bias in Blocks 2 and 3.

Importantly, controlling for baseline is often preferable to using difference scores, when examining associations with individual difference variables. Difference scores do not capture any information about the association between baseline scores and mid-task scores, instead imposing a linear restriction on their slopes when predicting outcome variables of interest; thus, the specific influence of baseline scores vs. scores at a second time point on a criterion variable cannot be identified when using difference scores (Allison, 1990; Edwards, 1996; Whittenborn, 1951). Controlling for baseline allows you to partial out variance in your performance measure that is shared with variance in baseline performance; this is important, because difference scores can be dependent on and correlated with baseline scores (Allison, 1990; Edwards, 1994; Edwards, 1996; Whittenborn, 1951). In the current design, controlling for Block 1 values of response bias when examining associations of a given variable with bias in Blocks 2 and 3 allows us to examine participants' deviation from their expected level of response bias relative to other participants; such models yield outcome variables that are often more meaningful and informative than simple difference scores (Edwards, 1994; Edwards, 1996; Whittenborn, 1951). Indeed, response bias in Block 1 was highly negatively correlated with difference scores in bias from Block 1 to 2 , in the current dataset $(\mathrm{r}=-.52, \mathrm{p}<.001)$, suggesting that controlling for baseline might be a better approach than using simple difference scores. Nonetheless, we also present analyses using difference scores for our direct replication aims, in an effort to mirror Pizzagalli's original study (2005) as closely as possible. 


\section{Questionnaire Measures}

Participants were administered a variety of questionnaires to measure personality ${ }^{2}$ and psychopathology. Peer reports were also collected for Big Five measures, from people who knew participants well, and at least one peer report was available for 236 participants. When multiple peers provided ratings for a given participant, they were averaged to create a single peer-report score.

Beck Depression Inventory (BDI-II). The BDI-II is a 21-item, 4-point Likert-format (0 for symptom absent and 3 for severe symptoms) self-report inventory used to assess presence and severity of depressive symptoms (Beck et al., 1996). The BDI-II exhibits high internal consistency, as well as external validity in predicting clinician ratings and scores on other validated depression measures, in both clinical and general population samples. In addition to overall scores, two sub-scores were created from the BDI data, in order to replicate analyses conducted by Pizzagalli et al. (2005). First, a score was computed for BDI items associated with anhedonic symptoms (“BDI anhedonic sub-score”): loss of pleasure (item \#4), loss of interest (item \#12), loss of energy (item \#15), and loss of interest in sex (item \#21) (Joiner et al., 2003). An additional sub-score was computed for melancholic depression (Pizzagalli et al., 2004) — a subtype of major depressive disorder characterized by pervasive anhedonia (Rush \& Weissenburger, 1994) — by summing scores of BDI items that map onto the DSM-IV criteria for melancholia: loss of pleasure (item \#4), guilty feelings (item \#5), agitation (item \#11), loss of interest (item \#12), early morning awakening (item \#16b), and loss of interest in sex (item \#21) (Pizzagalli et al., 2004). All BDI scores were logarithmically transformed to approximate normality, as

\footnotetext{
${ }^{2}$ We administered both the Big Five Aspect Scales (BFAS; DeYoung et al., 2007) and Big Five Inventory (BFI; John et al., 2008) because 1) administering multiple scales that assess the same construct allows for the creation of latent personality variables that can increase reliability, and 2) the BFAS specifically assesses aspect-level personality traits (e.g., enthusiasm and assertiveness for Extraversion, and volatility and withdrawal for Neuroticism), which are highly correlated — but distinct — constructs, while the BFI provides a high quality measure of overall Big Five domains (e.g., Extraversion and Neuroticism).
} 
they showed original skew values greater than 1.0 (Table 2). Results of all analyses were, however, substantively equivalent, whether or not BDI scores were log transformed.

Personality Inventory for DSM-5 (PID-5). The PID-5 (Krueger et al., 2012) questionnaire includes 220 items rated on a 4-point Likert scale (between 0 for very false or often false and 3 for very true or often true). This inventory was designed for maladaptive traits that are symptoms of personality disorder in the alternative model of personality disorder for DSM-5. The PID-5 comprises 25 primary trait scales that are grouped into five higher-order dimensions of Negative Affectivity, Detachment, Psychoticism, Antagonism, and Disinhibition (Krueger et al., 2012). For the present study, we used the Depressivity and Anhedonia scales, and scores were logarithmically transformed to approximate normality (original skewness $=1.43 \& 1.65$, respectively).

Big Five Aspect Scales (BFAS). The BFAS (DeYoung, Quilty, \& Peterson, 2007) consists of 100 items that require response ratings based on a 5-point Likert scale ranging from 1 (strongly disagree) to 5 (strongly agree). The questionnaire subdivides each of the Big Five into two component aspects (DeYoung et al., 2007), each assessed by 10 items, which can be averaged to generate 20-item Big Five scores. In the present study we used scores for Extraversion and Neuroticism.

Big Five Inventory (BFI). The BFI (John, Naumann, \& Soto, 2008) was used to evaluate participants based on the Big Five factors of personality_Extraversion, Agreeableness, Conscientiousness, Neuroticism, and Openness to Experience. This measure consists of 44 items scored on a 5-point Likert scale (1 for disagree strongly and 5 for agree strongly). We used scores for Extraversion and Neuroticism.

\section{Analyses}

Statistical Power. Pizzagalli et al. (2005) found a negative correlation between change in response bias and melancholic depression $(r=-.28, p=.035, N=61)$. They also found a range of 
associations between their response-bias variables and self-report measures of depression and anhedonia, including measures taken at a follow-up visit. One effect they reported, between response bias and total depression at follow-up $(r=-.46, p<.025, N=25)$ is surprisingly large, considering that few variables that do not share method variance are correlated at this magnitude (Hemphill, 2003). Such large effects are likely to be inflated due to sampling variability in small samples. Given our sample of 299 and an alpha threshold of .05, we had 90\% statistical power to detect a correlation of \pm .19 or stronger, and $80 \%$ power to detect a correlation of \pm .16 .

Effects of Task Manipulation. A two-way repeated-measures ANOVA was conducted on accuracy, using block and type of stimulus as within-subject factors. Additionally, one-way repeatedmeasures ANOVAs were conducted separately for response bias and discriminability across each of the three blocks. In each instance, these ANOVA models were followed by dependent-samples t-tests.

Direct Replication of Depression Associations. Repeated measures ANOVA models were conducted to test the interaction of depressivity-by-block on response bias. Two models were created using BDI as either a categorical variable with two levels or a continuous variable. Matching the criteria used by Pizzagalli et al. (2005), the level of high BDI consisted of cases with total BDI scores greater than or equal to 16 , and low BDI consisted of cases with a total score less than or equal to 6 . Our second model, using continuous BDI scores, was incorporated to avoid the loss of statistical power using the extreme groups ANOVA as employed in Pizzagalli’s original analysis. Correlations were computed for each task performance variable and total BDI scores, as well as the two BDI subscales for Melancholic and Anhedonic depression. Finally, an independent-samples t-test was used to test the difference in BDI scores for participants with positive vs. negative response biases.

Follow-up Depression Analyses. In addition to our direct replications of the association of BDI scores with response bias, we used similar repeated-measures ANOVA models and independent- 
samples t-tests in conjunction with the Anhedonia and Depressivity scales of the PID-5. Following these tests, structural equation modeling was used to examine relations between latent factors for depression and response bias, thereby removing error variance associated with individual scales and allowing a more powerful test of the association between depression and reward sensitivity. Scores for BDI, PID-5 Anhedonia, and PID-5 Depressivity were used as indicators of a latent variable for depression, while response-bias values for each of the three blocks were used as indicators of a latent response-bias variable. Two models were fit to examine the prediction of 1) response bias across all three blocks, by latent depression, and 2) response bias in Blocks 2 and 3, by latent depression, controlling for Block 1 response bias. These two models allow us to examine two different operationalizations of reward sensitivity, one focusing on participants' general tendency to select the more frequently reward stimulus across all blocks and the other focusing on how this tendency develops throughout the task, relative to participants' baseline levels. Common fit indices were computed for all structural equation models.

Extension Analysis of Personality and Task Performance. To assess the relations of PRT performance and latent personality factors, an additional series of structural equation models was fit. All models were constructed using full information maximum likelihood estimation to allow use of peer ratings despite missing data for some participants. Personality measures were allowed to load on latent factors of Extraversion and Neuroticism, and additional latent variables were used to model peerreport method effects (for Extraversion and Neuroticism) ${ }^{3}$. For each of our models, we ran two versions

\footnotetext{
${ }^{3}$ These peer-report factors are not factors of substantive theoretical interest to be included as predictors of reward sensitivity, but rather, are methods factors to account for the shared variance among the given peer report measures. Thus, their correlation with our predictor variables of interest were set to zero and they were not used as predictors of response bias in our models. This is not, however, to say that peer-and self- report measures of one personality trait are uncorrelated; they certainly are. Peer- and self- report measures of $\mathrm{E}$ (and N) share a substantial portion of variance, but this shared variance is already captured by our primary $\mathrm{E}$ ( and $\mathrm{N}$ ) latent variables - the peer-report measures load onto both the peer methods factors and the primary personality latent variables.
} 
of the model (mirroring our above models for depression), one in which the criterion latent variable was made up response bias of indicators from each of the three blocks and one in which the criterion latent variable was made up of response bias indicators from only Blocks 2 and 3 and response bias from Block 1 was included as a predictor variable (allowing us to control for participants' baseline response bias). Our first set of models examine the effects of Extraversion. Then, we examine the effects of Extraversion and Neuroticism, while modeling their associated variance in depression using a hierarchically nested latent variable for Depression, indicated by BDI and PID-5 Depressivity and Anhedonia, and loading onto both Neuroticism and Extraversion. In the construction of our models including both Extraversion and Neuroticism, the residual variances of peer and self-report versions of the same scales, for Extraversion and Neuroticism, were allowed to correlate. The latent variables of Extraversion and Neuroticism were allowed to correlate, as were the methods factors of PeerExtraversion and Peer-Neuroticism. Finally, we ran supplemental versions of our Extraversion and Neuroticism models that did not include a hierarchically nested Depression latent variable.

\section{Results}

\section{Effects of Task Manipulation}

Descriptive statistics for PRT performance variables are reported in Table 1. Discriminability was not correlated with response bias $(r=-.06, p=.31)$ or change in response bias $(r=.07, p=.20)$.

Table 1. Performance variables by block (means and standard deviations)

\begin{tabular}{lccc}
\hline & Block 1 & Block 2 & Block 3 \\
\hline Rich Accuracy & $0.82(0.11)$ & $0.85(.09)$ & $0.86(0.08)$ \\
Lean Accuracy & $0.72(0.13)$ & $0.73(0.13)$ & $0.72(0.15)$ \\
Accuracy & $0.77(0.10)$ & $0.79(0.09)$ & $0.79(0.10)$ \\
Discriminability & $0.58(0.27)$ & $0.64(0.28)$ & $0.66(0.30)$
\end{tabular}




\begin{tabular}{lccc} 
Response Bias & $0.13(0.19)$ & $0.18(0.19)$ & $0.20(0.21)$ \\
Rich RT (ms) & $546(155)$ & $519(151)$ & $521(150)$ \\
Lean RT (ms) & $577(166)$ & $560(166)$ & $567(172)$ \\
RT (ms) & $562(158)$ & $539(156)$ & $544(157)$ \\
\hline
\end{tabular}

Figure 2. Effects of task manipulation on performance
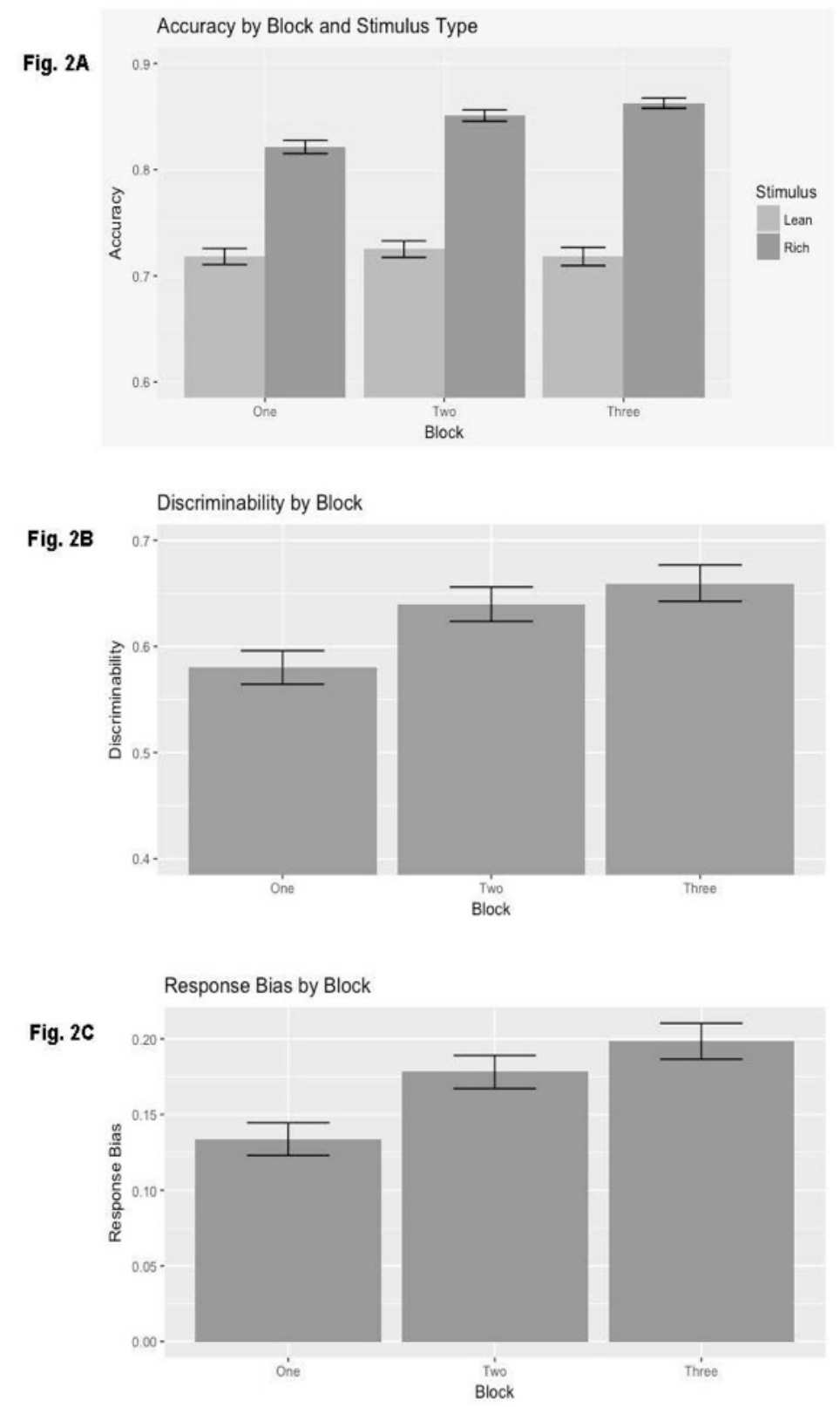
Accuracy (Fig. 2A). A two-way repeated measures ANOVA was computed for accuracy, using block and stimulus type as a within-subjects factor. There were significant main effects of block $\left(F_{(2,}\right.$ $297)=8.18, p<.001)$ and stimulus type $\left(F_{(1,298)}=391.72, p<.001\right)$, as well as a significant block-bystimulus interaction $\left(F_{(2,297)}=10.61, p<.001\right)$. Compared to accuracy in Block 1, overall accuracy was higher in Blocks $2\left(t_{(298)}=-3.71, p<.001\right)$ and $3\left(t_{(298)}=-3.88, p<.001\right)$. Accuracy did not significantly increase from Block 2 to $3\left(t_{(298)}=-0.60, p=.55\right)$. Across blocks, accuracy was higher for the rich stimulus compared to the lean stimulus $\left(t_{(298)}=19.25, p<.001\right)$.

Response Bias (Fig. 2B). A repeated measures ANOVA was computed for response bias, using block as a within-subjects factor. There was a significant main effect of block on response bias $\left(F_{(2,297)}\right.$ $=12.15, p<.001)$, namely, response bias increased significantly from Block 1 to Blocks $2\left(t_{(298)}=-\right.$ $2.88, p=.004)$ and $3\left(t_{(298)}=-4.03, p<.001\right)$, but not from Block 2 to Block $3\left(t_{(298)}=-1.26, p=.21\right)$.

Discriminability (Fig. 2C). A repeated measures ANOVA was computed for discriminability, using block as a within-subjects factor. There was a significant effect of block on discriminability $\left(F_{(2,}\right.$ 297) $=13.83, p<.001)$, with discriminability increasing significantly from Block 1 to Blocks $2\left(t_{(298)}=\right.$ $2.63, p=.009)$ and $3\left(t_{(298)}=-3.40, p<.001\right)$, but not from Block 2 to Block $3\left(t_{(298)}=-0.84, p=.40\right)$.

\section{Attempted Direct Replication of Depression Associations}

Descriptive statistics and measures of internal consistency reliability_Cronbach's $\alpha$ (Cronbach, 1951) and $\omega_{t}$ (McDonald, 1999; Revell \& Condon, 2019)_-for self- and peer-report measures are reported in Table 2. The distribution of BDI scores is shown in Figure 3. Of note, 61 of our 299 participants (20\%) had "elevated BDI scores" using the criterion of total score $\geq 16$, used by Pizzagalli et al. (2005); the original study had 15 of 62 participants (24\%) in this BDI score range. A total of 77 participants had BDI scores that were indicative of at least mild depression, using Beck's original suggested cut-off ranges (Beck et al., 1996). 
Table 2. Descriptive statistics for questionnaire measures

\begin{tabular}{|c|c|c|c|c|c|}
\hline & Mean (SD) & Skew & Range & Cronbach's $\alpha$ & $\omega_{t}$ \\
\hline \multicolumn{6}{|l|}{ Self-Report } \\
\hline BDI Total & $12.00(8.08)$ & 1.56 & 46.00 & .90 & .90 \\
\hline BDI Anhedonic & $1.65(1.76)$ & 1.42 & 9.00 & .66 & .67 \\
\hline BDI Melancholic & $4.14(2.49)$ & 1.13 & 13.00 & .61 & .71 \\
\hline PID-5 Depressivity & $1.43(0.50)$ & 1.60 & 3.00 & .91 & .92 \\
\hline PID-5 Anhedonia & $1.65(0.54)$ & 1.19 & 2.88 & .84 & .86 \\
\hline BFAS Neuroticism & $2.59(0.67)$ & .26 & 3.55 & .90 & .90 \\
\hline BFAS Withdrawal & $2.70(0.71)$ & .23 & 3.70 & .81 & .82 \\
\hline BFAS Volatility & $2.49(0.80)$ & .44 & 3.90 & .89 & .90 \\
\hline BFI Neuroticism & $2.56(0.78)$ & .15 & 3.75 & .85 & .85 \\
\hline BFAS Extraversion & $3.69(0.57)$ & -.42 & 3.40 & .86 & .87 \\
\hline BFAS Assertiveness & $3.63(0.65)$ & -.43 & 3.30 & .83 & .84 \\
\hline BFAS Enthusiasm & $3.74(0.73)$ & -.51 & 3.70 & .84 & .85 \\
\hline BFI Extraversion & $3.30(0.82)$ & -.13 & 4.00 & .87 & .88 \\
\hline \multicolumn{6}{|l|}{ Peer-Report } \\
\hline BFAS Neuroticism & $2.61(0.61)$ & .21 & 2.82 & & \\
\hline BFAS Withdrawal & $2.58(0.59)$ & .31 & 2.73 & & \\
\hline BFAS Volatility & $2.63(0.73)$ & .26 & 3.35 & & \\
\hline BFI Neuroticism & $2.63(0.71)$ & .23 & 3.71 & & \\
\hline BFAS Extraversion & $3.75(0.47)$ & -.42 & 2.62 & & \\
\hline BFAS Assertiveness & $3.67(0.52)$ & -.20 & 2.90 & & \\
\hline BFAS Enthusiasm & $3.83(0.58)$ & -.71 & 3.30 & & \\
\hline BFI Extraversion & $3.56(0.68)$ & -.09 & 3.46 & & \\
\hline
\end{tabular}


Figure 3. Beck Depression Inventory (BDI-II) score distribution

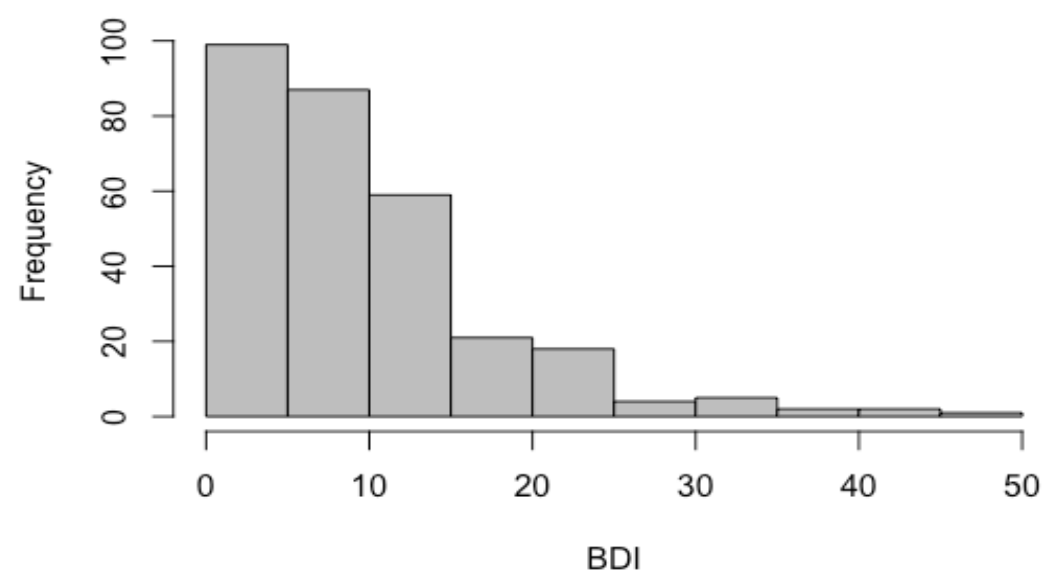

Repeated measures ANOVA models were computed to determine whether there was a blockby-depressivity interaction on response bias. No significant interaction was found between block and BDI group $\left(F_{(2,161)}=0.47, p=.63\right)$. Because this test reduces power relative to treating BDI score as a continuous variable and using the whole sample, we also conducted a repeated measures ANOVA including block and continuous BDI scores as predictors of response bias, for which there was also no significant interaction $\left(F_{(2,296)}=.16, p=.69\right)$. Pearson correlations were used to further investigate associations between PRT performance variables and BDI. No correlations were significant at an alpha level of .05 (Table 3).

Table 3. Pearson correlations between depression-related variables and task performance

\begin{tabular}{lccccc}
\hline & Accuracy & Discriminability & Response Bias & $\Delta$ RB1-2 & $\Delta$ RB1-3 \\
\hline BDI & -.07 & -.03 & -.07 & .01 & -.02 \\
BDI Anhedonic & -.05 & .04 & -.05 & .04 & -.02 \\
BDI Melancholic & -.08 & -.02 & -.09 & .02 & .00 \\
PID-5 Depressivity & -.05 & -.07 & -.05 & -.02 & -.09 \\
PID-5 Anhedonia & -.07 & -.05 & -.07 & -.02 & -.06 \\
\hline
\end{tabular}


Of particular note, the $95 \%$ confidence interval around the correlation between change in response bias and melancholic depression in the current sample, $[-.13, .13]$, did not contain -.28, the correlation detected and presented as a key finding in Pizzagalli et al.'s (2005) original study. Finally, contrary to the original findings, individuals with positive vs. negative changes response-bias showed no significant differences in overall BDI $\left(t_{(296)}=0.18, p=.85\right)$ or its Anhedonic $\left(t_{(296)}=-0.35, p=.72\right)$ or Melancholic sub-scores $\left(t_{(296)}=-0.06, p=.95\right)$.

\section{Follow-up Depression Analyses}

After testing for direct replication of the associations between PRT performance and BDI, we followed up these analyses with similar tests for the Depressivity and Anhedonia scales of the PID-5. There were no significant associations between these PID-5 scales and PRT performance (Table A1). Similarly, there was no significant interaction of task block with PID-5 Depressivity $\left(F_{(2,292)}=1.51, p\right.$ $=.22)$ or PID-5 Anhedonia $\left(F_{(2,292)}=0.63, p=.43\right)$, in predicting response bias. Finally, individuals with positive vs. negative response-bias values showed no significant differences in PID-5 Depressivity $\left(t_{(292)}=0.68, p=.50\right)$ or PID-5 Anhedonia $\left(t_{(292)}=1.00, p=.32\right)$.

Next, we used structural equation models to extend the analyses from Pizzagalli's original study. All structural equation models had acceptable fit, as indicated by RMSEA values less than .085 and TLI values greater than .950 (Table 4). Results of a structural equation model predicting reward sensitivity, modeled as the shared variance of response bias across the three blocks from shared variance in BDI, PID-5 Depressivity, and PID-5 Anhedonia, are displayed in Figure 4a. Latent depression was not a significant predictor of Reward Sensitivity, as modeled using shared variance in response bias across all three blocks $(\beta=-.05,95 \%$ CI $[-.19, .09]$; Figure $4 a)$. Depression also did not significantly predict the shared variance of response bias in Blocks 2 and 3, when controlling for response bias from Block 1 ( $\beta=-.06,95 \%$ CI [-.19, .07]; Figure 4b). 
Figure 4. Structural equation models of depression predicting response bias (a) and response bias controlling for baseline (b)

Fig 4a
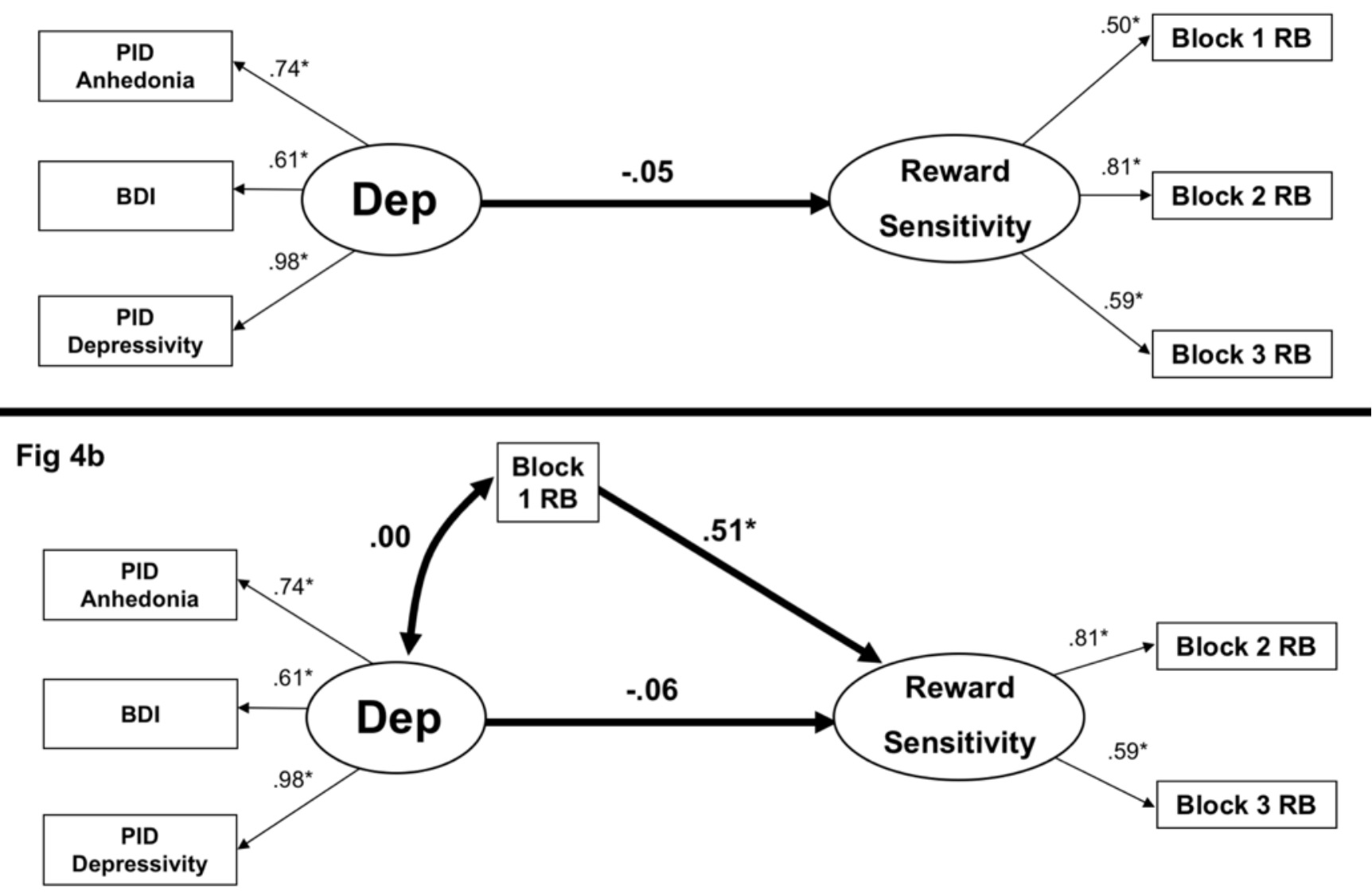
Table 4. Fit statistics for structural equation models

\begin{tabular}{|c|c|c|c|c|c|c|}
\hline Models & RMSEA & 95\% C.I. & $\chi^{2}$ & $\mathrm{p}$ & TLI & CFI \\
\hline Depression and Response Bias & .000 & {$[.000, .020]$} & 3.1 & .927 & 1.0 & 1.0 \\
\hline Depression and Response Bias Controlling for Baseline & .000 & {$[.000, .031]$} & 2.8 & .900 & 1.0 & 1.0 \\
\hline E and Response Bias & .078 & {$[.046, .111]$} & 31.0 & .001 & .957 & .978 \\
\hline E and Response Bias Controlling for Baseline & .081 & {$[.048, .115]$} & 910.9 & .001 & .954 & .978 \\
\hline E, N, Depression, and Response Bias & .061 & {$[.046, .075]$} & 134.3 & $<.000$ & .959 & .971 \\
\hline E, N, Depression, and Response Bias Controlling for Baseline & .062 & {$[.047, .076]$} & 132.9 & $<.001$ & .957 & .971 \\
\hline $\mathrm{E}, \mathrm{N}$, and Response Bias & .028 & {$[.000, .053]$} & 40.6 & 169 & .993 & .996 \\
\hline $\mathrm{E}, \mathrm{N}$, and Change in Response Bias & .030 & {$[.000, .055]$} & 39.2 & 148 & .992 & .995 \\
\hline
\end{tabular}

\section{Extension Analysis of Personality and Task Performance}

Pearson correlations between measures of personality and PRT performance variables are presented in Table A1. Several Extraversion variables showed significant positive correlations with change in response bias and with response bias aggregated over Blocks 2 and 3 (Table A1). Next, we used structural equation models to examine the effects of latent Extraversion on Reward Sensitivity as operationalized using response bias aggregated across all blocks (Figure 5a) and bias in Blocks 2 and 3 controlling for Block 1 (Figure 5b). Extraversion was a significant positive predictor of response bias in Blocks 2 and 3, controlling for bias in Block $1(\beta=.14,95 \%$ CI $[.02, .27]$; Figure 5b), but the association between Extraversion and response bias across all three blocks did not reach statistical significance $(\beta=.13,95 \% \mathrm{CI}[-.01, .26]$; Figure 5a); nonetheless, the associations for both models were both in the positive direction and were nearly identical in their magnitude, as evidenced by highly overlapping confidence intervals. 
Fig 5a

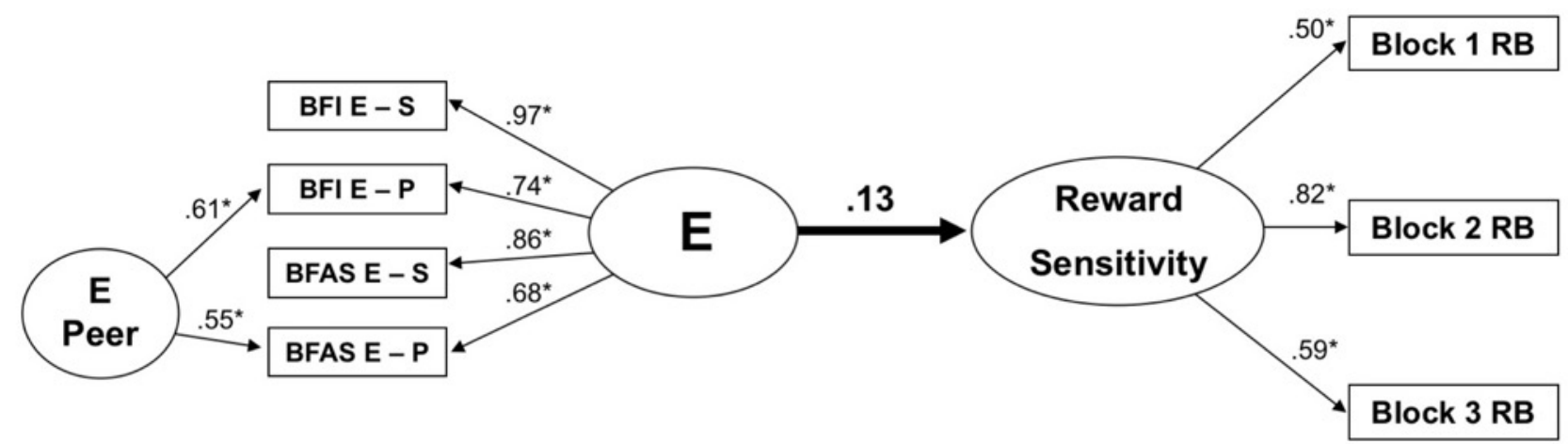

Fig 5b

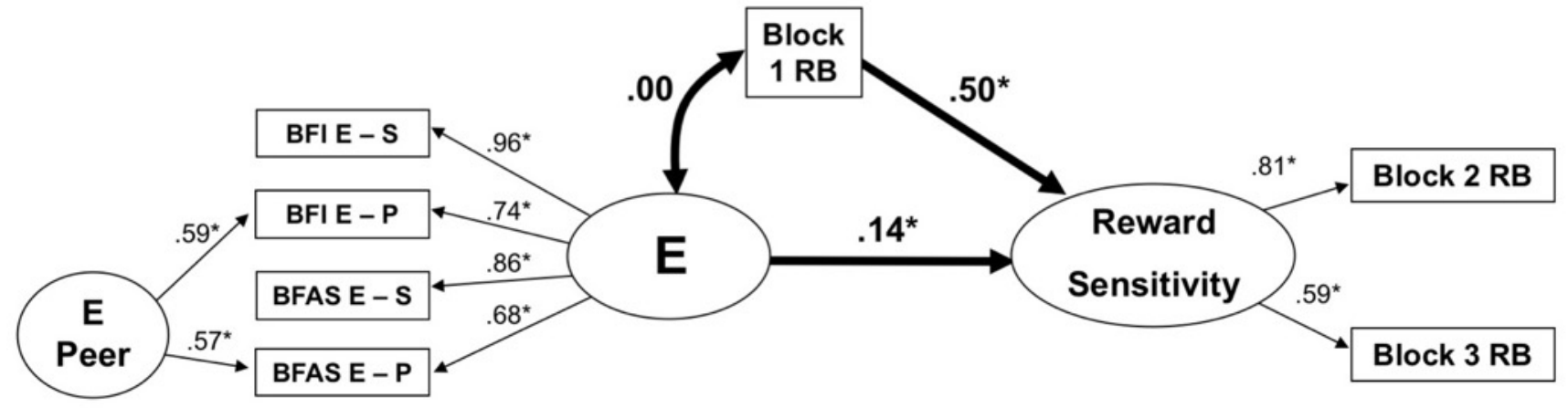

Next, we ran models predicting Reward Sensitivity from both Extraversion and Neuroticism, including Depression as a hierarchically nested latent variable loading onto both personality traits (Figures 6 and 7). Latent Depression had a negative loading from Extraversion $(\lambda=-.32,95 \%$ CI [-.43, $-.22])$ and a positive loading from Neuroticism $(\lambda=.61,95 \%$ CI $[.52, .70])$. Extraversion (and associated variance in depression) positively predicted Reward Sensitivity, modeled both as the shared variance of response bias across all three blocks $(\beta=.17,95 \% \mathrm{CI}[.01, .32]$; Figure 6$)$ and as response bias in Blocks 2 and 3, using Block 1 bias as a covariate $(\beta=.17,95 \%$ CI $[.03, .32]$; Figure 7$)$.

Neuroticism (and associated variance in depression) did not significantly predict response bias in either model. Results were substantively similar using models that did not include a hierarchically nested 
Depression latent variable, with Extraversion showing positive associations with response bias, whether or not Block 1 bias was controlled for (Figures A1 and A2).

Figure 6. Model of Extraversion, Neuroticism, and response bias

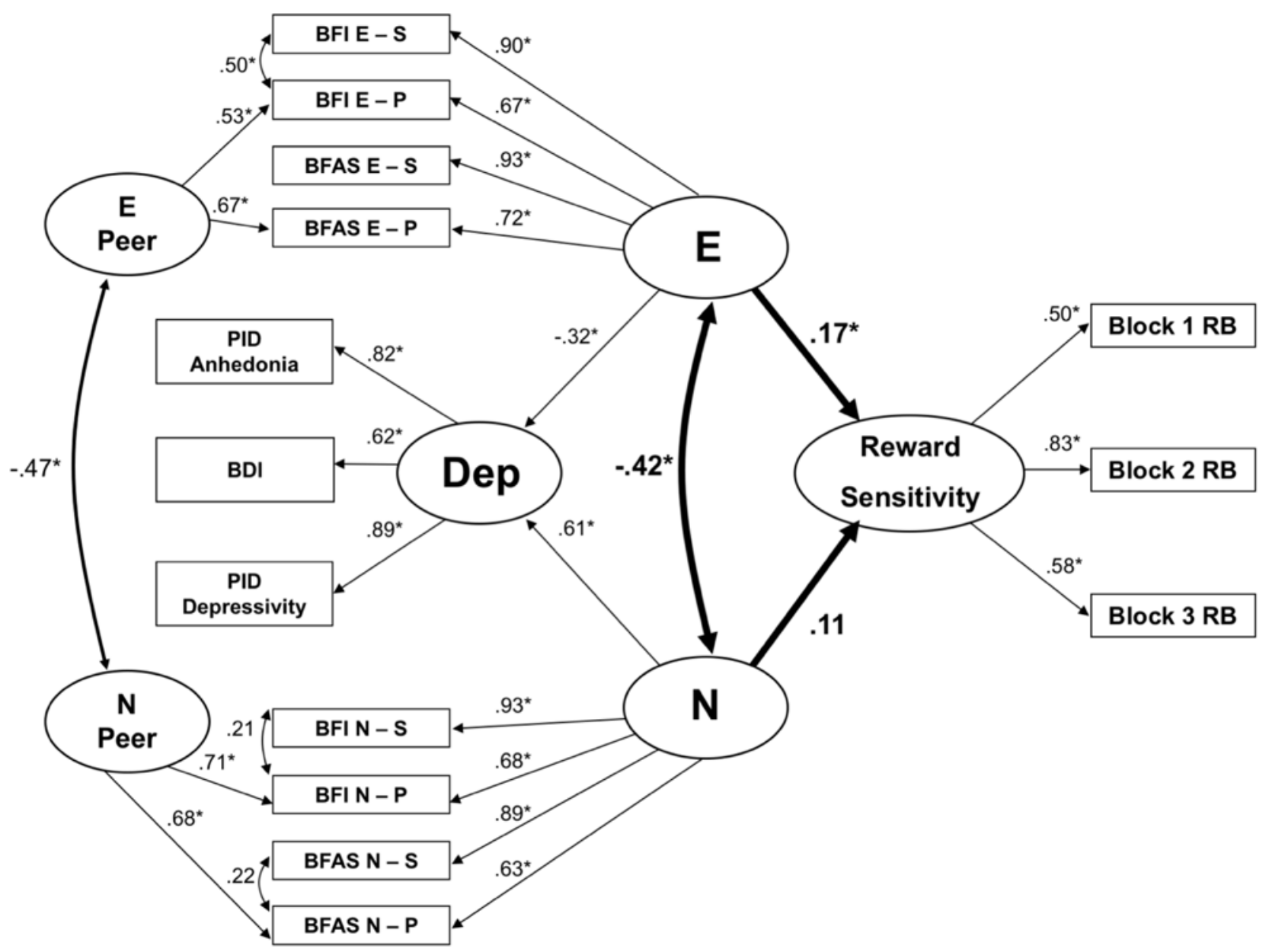


Figure 7. Model of Extraversion, Neuroticism, and response bias controlling for baseline

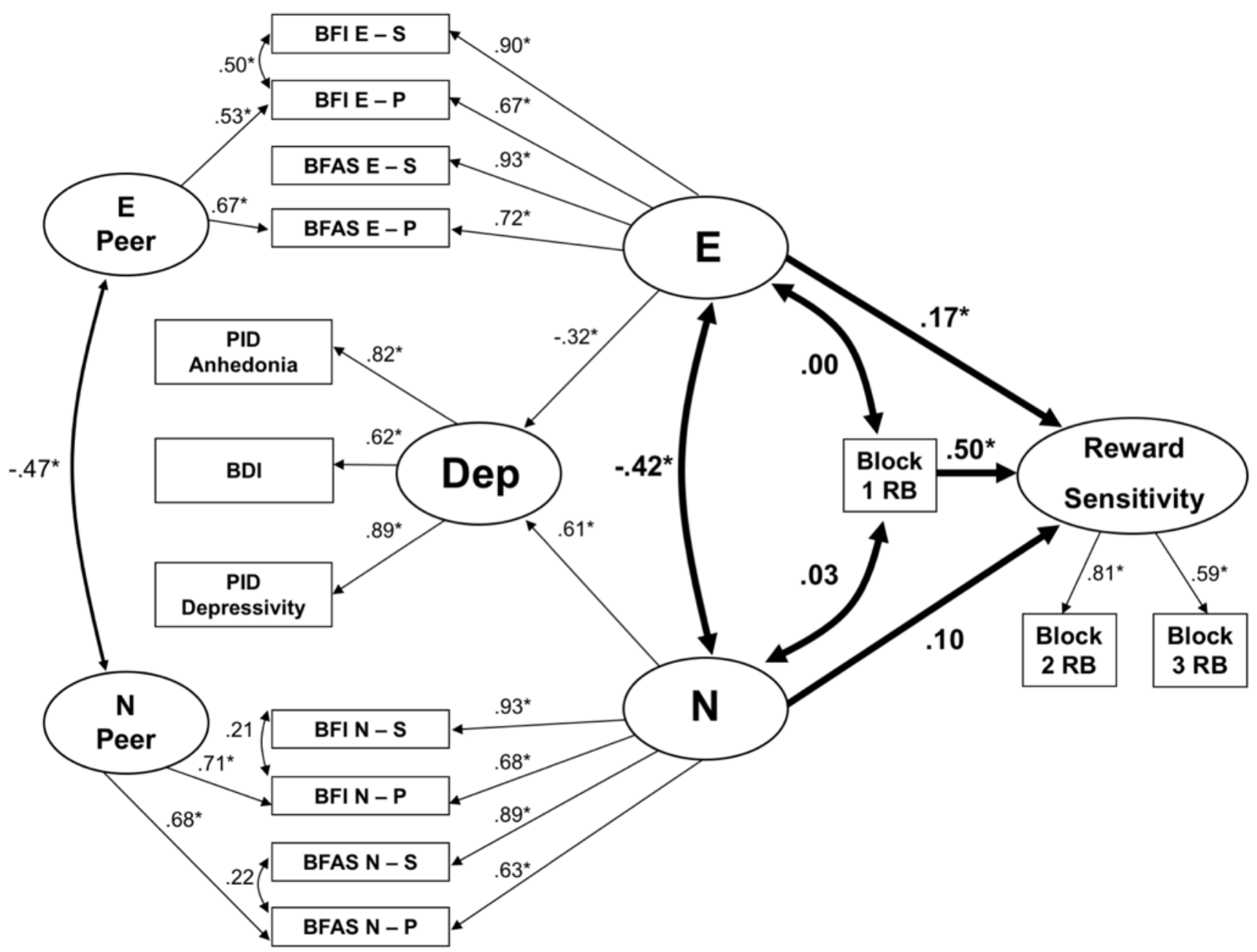

\section{Discussion}

The first aim of the current study was to replicate previous work linking performance on the PRT with depressive symptomatology, as measured by the Beck Depression Inventory (Pizzagalli et al., 2005). Specifically, we hypothesized that BDI scores would be negatively associated with response bias, change in response bias, and response bias controlling for baseline. However, we found no associations between response-bias variables and BDI and replicated none of the significant effects 
from the original study. Neither were there significant associations with the Depressivity or Anhedonia scales of the PID-5, which we used to test a conceptual replication. Our structural equation models testing the effects of depression on PRT performance also showed no effects. It is worth noting, however, that our participants' group-level response to the PRT manipulation did replicate previous findings, as participants, on average, did develop a response bias toward the more frequently rewarded stimulus, and the strength of this bias increased across the three blocks (Pizzagalli et al., 2005).

Given the much greater statistical power of the current study than the original, these null findings suggest that the original results may have been false positives. The finding from the original study that the Melancholic subscale of the BDI was significantly correlated with response bias was based on a sample size of 61 individuals (Pizzagalli et al., 2005), a sample with low statistical power for detecting all but the largest effect sizes regularly observed in individual differences research (Gignac \& Szodorai, 2016; Richard et al., 2003). Moreover, some findings presented in the original study were detected after dichotomizing key variables, which can lead to severe reduction of statistical power (Cohen, 1983; MacCallum et al., 2002), thereby increasing the likelihood that any significant results are false positives.

\section{The Role of Extraversion in Reward Sensitivity and Depression}

Although the association of reward sensitivity with depressive symptomatology did not replicate in the current study, we did find support for our hypothesis that reward sensitivity would be associated with Extraversion. In an effort to extend the results of previous work by Pizzagalli et al. and to integrate them with current theory and research on personality and dimensional models of psychopathology, we tested associations of PRT performance with personality dimensions related to depression, hypothesizing that reward sensitivity — modeled both as response bias and as response bias controlling for baseline - would be positively associated with levels of Extraversion but not with levels 
of Neuroticism. Our hypotheses were largely confirmed, though one of our six SEMs testing the relation between Extraversion and reward sensitivity did not quite reach statistical significance, consistent with research showing associations between Extraversion and reward responsiveness as measured in other behavioral tasks (Ávila \& Parcet, 2002; Robinson, Moeller, \& Ode, 2010). The association of Extraversion with reward sensitivity evident in behavioral tasks aligns well with evidence that variation in the brain's reward system is a major neural correlate of Extraversion (Allen \& DeYoung, 2017; Smillie \& Wacker, 2014). Theories of the biological basis of Extraversion emphasize the role of the dopaminergic incentive reward system, which is involved in the kind of reward learning that occurs in the PRT (DePue \& Collins, 1999; DeYoung, 2013).

Our findings suggest that levels of Extraversion, not depressivity, are associated with reward sensitivity. More precisely, any association that depressivity has with reward sensitivity is likely to be due to its association with Extraversion. The models in Figures 6 and 7 do imply at least a weak association between depression and reward sensitivity because depression is an indicator of Extraversion (though not as strongly as it is an indicator of Neuroticism). However, it also suggests that investigations into reward-function deficits as a transdiagnostic factor underlying depression would be better off investigating the Detachment (low Extraversion) symptom dimension specifically, rather than focusing on depression symptoms more broadly. Indeed, the association between Extraversion and reward sensitivity becomes stronger after controlling for variance in Neuroticism, suggesting that reward sensitivity is related to Extraversion and associated variance in depression, rather than to the depression variance associated with Neuroticism. Our findings support the value of research on psychopathology that is theoretically driven and focuses on empirically validated dimensional constructs that bridge the gap between psychopathology and personality (DeYoung \& Krueger, 2018). 
In addition to corroborating research on the role of reward sensitivity in Extraversion, our findings support research suggesting depression is related to both negative affect and lack of reward responsiveness, with these symptoms related to Neuroticism and Extraversion, respectively (Kotov et al., 2010). This conceptualization is in line with RDoC's distinction between positive and negative valence systems and with many traditional models of depressive symptomatology (Barch et al., 2016; Clark \& Watson, 1991). Findings are also interesting when interpreted in conjunction with recent evidence that performance on the PRT predicts positive response of depression patients to bupropion but not sertraline (Ang et al., 2020); this is relevant to possible distinct mechanisms of depression related to Neuroticism vs. Extraversion, as bupropion acts on dopamine (though also norepinephrine), a neurotransmitter theoretically and empirically linked to Extraversion (Ascher et al., 1995; DePue \& Collins, 1999), while sertraline acts primarily on serotonin, which is related to Neuroticism (De Vane et al., 2002; Wright et al., 2019). Future studies investigating cognitive and affective mechanisms of depression - and their potential amelioration through psychopharmacological and behavioral interventions - might benefit from incorporating measures of Extraversion and Detachment, in addition to measures more closely related to Neuroticism and Negative Affect.

\section{Reliability and Validity Considerations}

When using behavioral tasks to assess affective and cognitive mechanisms, such as reward sensitivity, it is important to ensure one's tasks are both reliable in their measurement of individual differences and valid in measuring the constructs they seek to represent. Merely having face validity does not necessarily make a measure reliable or valid. Moreover, even tasks that are able to detect robust effects at the group level (e.g., tests of implicit bias and self-regulation) often fail to produce reliable measurement of individual differences (Dang et al., 2020; Hedge et al., 2018; Enkavi et al., 2019a; 2019b; Schnabel et al., 2008). Many of the most frequently used behavioral tasks emerge from 
the cognitive and social psychology literatures, where there is a focus on reducing individual differences in task performance in efforts to reduce measurement error; interindividual variability on task performance is often seen as an obstacle to be overcome, rather than a substantive variable to be tested (Cronbach, 1957). This leads to problems when these tasks are then adopted for individual differences research, as low between-subject variability inherently reduces the reliability, and in turn, the validity of these measures (Hedge et al., 2018). Compared to tasks from social and cognitive psychology, measures emerging from the clinical psychology literature, where the PRT originates, often fare better in evaluations of their psychometric properties, as individual differences are of primary interest (Barch et al., 2016; Pinkham et al., 2018). When it comes to Pizzagalli's PRT in particular, there is some work - albeit limited in scope and hindered by low statistical powerestablishing the task's reliability and validity.

The two main ways to quantify the reliability of a task are internal consistency and test-retest reliability. The fact that all three response bias variables (for Blocks 1 through 3) are correlated with one another and load significantly onto a single latent variable in our current sample provides evidence of internal consistency. As mentioned in our methods section, there is also evidence that the PRT has acceptable split-half reliability, further evidence for the task's internal consistency (Lawlor et al., 2019). In comparison, the evidence for test-retest reliability is limited to two studies with very small samples: $\mathrm{r}=.57(\mathrm{~N}=25$; Pizzagalli et al., 2005) and $\mathrm{r}=.62(\mathrm{~N}=16$; Santesso et al., 2008). The PRT is, however, currently under evaluation as part of two major research efforts using large clinical samples: The Cognitive Neuroscience Test Reliability and Clinical Applications for Schizophrenia (CNTRACs) Consortium (Barch et al., 2017; Gold et al., 2012) and The Establishing Moderators and Biosignatures of Antidepressant Response for Clinical Care for Depression (EMBARC) Study (Trivedi et al., 2016; Webb et al., 2016; Webb et al., 2020). These efforts should certainly help to further 
establish (or refute) the PRT's reliability as a useful measure for personality and psychopathology research.

It is also important to consider convergent validity of the PRT with other tasks and variables we would expect to be related. Many researchers using the PRT — as well as workgroups evaluating this and similar measures (e.g., the National Advisory Mental Health Council Workgroup on Tasks and Measures for RDoC) — have framed its published associations with constructs of interest such as depression and anhedonia, supplemented with neuroimaging and candidate gene research relating performance to brain regions and neurochemicals related to reward processing, as evidence of convergent validity (Delgado et al., 2016). Nonetheless, a majority of these studies (particularly those with neuroimaging or genetic components) are lacking in statistical power (Bogdan et al., 2006; Bogdan et al., 2011; Bress \& Hajcak, 2013; Liu et al., 2015; Pizzagalli et al., 2007; Pizzagalli et al., 2008; Santesso et al., 2008; Webb et al., 2016; Whitton et al., 2016). Thus, further research establishing the reliability and convergent validity of the PRT is essential.

\section{Limitations}

In addition to these broader issues of reliability and validity, there are a few other limitations worth discussing. Although our current findings suggest that performance on PRT is not correlated with depression in a community sample, we did not investigate participants with severe levels of anhedonia or depression, as was done in studies using the task in clinical populations (e.g., Pizzagalli et al., 2008a, 2008b; Vrieze et al., 2013). Response bias on the PRT may, in fact, be reduced among depressed individuals with more extreme levels of anhedonia, even if the association is not strong enough to be detected in the general population, though other recent studies in clinical samples also call this association into question (Lawlor et al., 2019). This possibility could not explain, however, our failure to replicate the findings of Pizzagalli et al. (2005), given that BDI scores in our sample were 
comparable or higher than in the original undergraduate sample. Additionally, the lack of association between PRT performance and questionnaire measures of anhedonia and depression does not speak to the question of whether these characteristics might be related to reward sensitivity assessed using different behavioral tasks. Future research in this area could address these limitations by incorporating additional measures of reward sensitivity and recruiting additional participants in the clinical range of depressive symptomatology. In particular, using latent variable frameworks to assess the relation between joint personality-psychopathology dimensions and reward sensitivity modeled as shared variance of performance on multiple tasks could be particularly useful for addressing several of the limitations noted here (Blain et al., 2020a; Blain et al., 2020b; Campbell \& Fiske, 1959; Nosek et al., 2007).

\section{Conclusion}

In summary, results of the current study failed to replicate previous findings and suggest that reduced reward response observed in previous studies may have been driven by low-levels of Extraversion or by the presence of Detachment-related psychopathology, rather than by depressive symptoms more generally. Thus, our findings emphasize the importance of transdiagnostic research and the conceptualization of depression as related to both high Neuroticism and low Extraversion. They also provide support for the theory that reward sensitivity is a core mechanism of Extraversion. Finally, they underscore the importance of replication with adequate sample sizes in moving toward reproducibility in psychological research. 


\section{References}

Allen, T. A., \& DeYoung, C. G. (2017). Personality neuroscience and the Five Factor Model. In T. A. Widiger (Ed.). Oxford Handbook of the Five Factor Model (pp. 319-349). New York: Oxford University Press.

Allen, T. A., Rueter, A. R., Abram, S. V., Brown, J. S., \& Deyoung, C. G. (2017b). Personality and neural correlates of mentalizing ability. European Journal of Personality, 31(6), 599-613.

Allison, P. D. (1990). Change scores as dependent variables in regression analysis. Sociological Methodology, 93-114.

Andreasen, N. C., Berrios, G. E., Bogerts, B., Brenner, H. D., Carpenter, W. T., Crow, T. J., ... \& Lewine, R. R. J. (2012). Negative Versus Positive Schizophrenia. Springer Science \& Business Media.

Ang, Y. S., Kaiser, R., Deckersbach, T., Almeida, J., Phillips, M. L., Chase, H. W., ... \& Weissman, M. (2020). Pretreatment reward sensitivity and frontostriatal resting-state functional connectivity are associated with response to bupropion after sertraline non-response. Biological Psychiatry. https://doi.org/10.1016/j.biopsych.2020.04.009

Ascher, J. A., Cole, J. O., Colin, J. N., Feighner, J. P., Ferris, R. M., Fibiger, H. C., ... \& Richelson, E. (1995). Bupropion: a review of its mechanism of antidepressant activity. The Journal of Clinical Psychiatry, 56(9), 395-401.

Ávila, C., \& Parcet, M. A. (2002). Individual differences in reward sensitivity and attentional focus. Personality and Individual Differences, 33, 979-996. https://doi.org/10.1016/S01918869(01)00207-0 
Barch, D. M., Carter, C. S., Gold, J. M., Johnson, S. L., Kring, A. M., MacDonald III, A. W., ... \& Strauss, M. E. (2017). Explicit and implicit reinforcement learning across the psychosis spectrum. Journal of Abnormal Psychology, 126(5), 694.

Barch, D. M., Oquendo, M. A., Pacheco, J., \& Morris, S. (2016). Behavioral assessment methods for RDoC constructs: A report by the National Advisory Mental Health Council Workgroup on tasks and measures for RDoC. Washington, DC: National Institutes of Mental Health.

Beck, A. T., \& Steer, R. A. (1987). Manual for Beck Depression Inventory. TX, San Antonio: The Psychological Corporation.

Beck, A. T., Steer, R. A., \& Brown, G. K. (1996). BDI-II: Beck Depression Inventory Manual. (2 ${ }^{\text {nd }}$ ed.) TX, San Antonio: The Psychological Corporation.

Beck, A. T., Steer, R. A., \& Garbin, M. G. (1988). Psychometric properties of the Beck Depression Inventory: Twenty-five years of evaluation. Clinical Psychology Review, 8, 77-100. http://dx.doi.org/10.1016/0272-7358(88)90050-5

Beck, A. T., Ward, C. H., Mendelson, M., Mock, J., \& Erbaugh, J. (1961). An inventory for measuring depression. Archives General Psychiatry, 4, 561-571. http://dx.doi.org/10.1001/archpsyc.1961.01710120031004

Blain, S.D., Grazioplene, R.G., Ma, Y., \& DeYoung, C.G. (2020a). Toward a neural model of the Openness-psychoticism dimension: Functional connectivity of the default and frontoparietal control networks. Schizophrenia Bulletin, 46, 540-551. http://dx.doi.org/10.1093/schbul/sbz103

Blain, S. D., Longenecker, J. M., Grazioplene, R. G., Klimes-Dougan, B., \& DeYoung, C. G. (2020b). Apophenia as the disposition to false positives: An underlying framework for positive symptoms of the Openness-psychoticism dimension. Journal of Abnormal Psychology, 129(3), 279-292. http://dx.doi.org/10.31234/osf.io/d9wkc 
Bogdan, R., \& Pizzagalli, D. A. (2006). Acute stress reduces hedonic capacity: Implications for depression. Biological Psychiatry, 60, 1147-1154.

Bogdan, R., Santesso, D. L., Fagerness, J., Perlis, R. H., \& Pizzagalli, D. A. (2011). Corticotropinreleasing hormone receptor type 1 (CRHR1) genetic variation and stress interact to influence reward learning. Journal of Neuroscience, 31(37), 13246-13254.

Boksem, M. A., Tops, M., Wester, A. E., Meijman, T. F., \& Lorist, M. M. (2006). Error-related ERP components and individual differences in punishment and reward sensitivity. Brain Research, 1101, 92-101. http://dx.doi.org/10.1016/j.brainres.2006.05.004

Bress, J. N., \& Hajcak, G. (2013). Self-report and behavioral measures of reward sensitivity predict the feedback negativity. Psychophysiology, 50(7), 610-616.

Brown, G. S., \& White, K. G. (2005). The optimal correction for estimating extreme discriminability. Behavior Research Methods, 37(3), 436-449.

Brown, G. S., \& White, K. G. (2009). Measuring discriminability when there are multiple sources of bias. Behavior Research Methods, 41(1), 75-84.

Campbell, D. T., \& Fiske, D. W. (1959). Convergent and discriminant validation by the multitraitmultimethod matrix. Psychological Bulletin, 56(2), 81.

Carver, C. S., \& White, T. L. (1994). Behavioral inhibition, behavioral activation, and affective responses to impending reward and punishment. The BIS/BAS Scales. Journal of Personality and Social Psychology, 67, 319-333. http://dx.doi.org/10.1037/0022-3514.67.2.319

Clark, L. A., \& Watson, D. (1991). Tripartite model of anxiety and depression: psychometric evidence and taxonomic implications. Journal of Abnormal Psychology, 100(3), 316.

Cohen, J. (1983). The cost of dichotomization. Applied Psychological Measurement, 7, 249-253. http://dx.doi.org/10.1177/014662168300700301 
Cohen, M. X., Young, J., Baek, J. M., Kessler, C., \& Ranganath, C. (2005). Individual differences in Extraversion and dopamine genetics predict neural reward responses. Cognitive Brain Research, 25, 851-861. http://dx.doi.org/10.1016/j.cogbrainres.2005.09.018

Corr, P. J. (2008). The Reinforcement Sensitivity Theory of Personality. Cambridge University Press. Costello, C. G. (1972). Depression: Loss of reinforcers or loss of reinforcer effectiveness? Behavior Therapy, 3, 240-247. https://doi.org/10.1016/S0005-7894(72)80084-4

Cronbach, L. J. (1951). Coefficient alpha and the internal structure of tests. Psychometrika, 16, 297334.

Dang, J., King, K. M., \& Inzlicht, M. (2020). Why Are Self-Report and Behavioral Measures Weakly Correlated? Trends in Cognitive Sciences, 24(4), 267-269.

De Vane, C. L., Liston, H. L., \& Markowitz, J. S. (2002). Clinical pharmacokinetics of sertraline. Clinical Pharmacokinetics, 41(15), 1247-1266.

Delgado, M. R., Glimcher, P. W., Hajcak, G., Pizzagalli, D. A., Treadway, M. T., Yerys, B. E. (2016). Positive Valence Systems Final Report. In Barch, D. M., Oquendo, M. A., Pacheco, J., \& Morris, S. Behavioral Assessment Methods for RDoC Constructs: A Report by the National Advisory Mental Health Council Workgroup on Tasks and Measures for RDoC. Washington, DC: National Institutes of Mental Health.

Depue, R. A., \& Collins, P. F. (1999). Neurobiology of the structure of personality: Dopamine, facilitation of incentive motivation, and Extraversion. Behavioral and Brain Sciences, 22, 491517. http://dx.doi.org/10.1017/S0140525X99002046

DeYoung, C. G. (2013). The neuromodulator of exploration: A unifying theory of the role of dopamine in personality. Frontiers in Human Neuroscience, 7, article 762. http://dx.doi.org/10.3389/fnhum.2013.00762 
DeYoung, C. G., \& Krueger R. F. (2018). A cybernetic theory of psychopathology. Psychological Inquiry, 29, 117-138. https://doi.org/10.1080/1047840X.2018.1513680

DeYoung, C. G., Quilty, L. C., \& Peterson, J. B. (2007). Between facets and domains: 10 aspects of the Big Five. Journal of Personality and Social Psychology, 93, 880-896. http://dx.doi.org/10.1037/0022-3514.93.5.880

Di Nicola, M., De Risio, L., Battaglia, C., Camardese, G., Tedeschi, D., Mazza, M., ... \& Siracusano, A. (2013). Reduced hedonic capacity in euthymic bipolar subjects: a trait-like feature? Journal of Affective Disorders, 147(1-3), 446-450.

Edwards, J.R. (1994). Regression analysis as an alternative to difference scores. Journal of Management, 20, 683-689.

Edwards, J. R. (1996). An examination of competing versions of the person-environment fit approach to stress. Academy of Management Journal, 39(2), 292-339.

Enkavi, A. Z., Eisenberg, I. W., Bissett, P. G., Mazza, G. L., MacKinnon, D. P., Marsch, L. A., \& Poldrack, R. A. (2019a). Large-scale analysis of test-retest reliabilities of self-regulation measures. Proceedings of the National Academy of Sciences, 116(12), 5472-5477.

Enkavi, A. Z., Eisenberg, I. W., Bissett, P. G., Mazza, G. L., MacKinnon, D. P., Marsch, L. A., \& Poldrack, R. A. (2019b). Reply to Friedman and Banich: Right measures for the research question. Proceedings of the National Academy of Sciences, 116(49), 24398-24399.

Fried, E. I. (2017). The 52 symptoms of major depression: Lack of content overlap among seven common depression scales. Journal of Affective Disorders, 208, 191-197.

Gignac, G. E., \& Szodorai, E. T. (2016). Effect size guidelines for individual differences researchers. Personality and Individual Differences, 102, 74-78. http://dx.doi.org/10.1016/j.paid.2016.06.069 
Goldberg, L. R. (1992). The development of markers for the big five factor structure. Psychological Assessment, 4, 26-42. http://dx.doi.org/10.1037/1040-3590.4.1.26

Gottesman, I. I., \& Gould, T. D. (2003). The endophenotype concept in psychiatry: etymology and strategic intentions. The American Journal of Psychiatry, 160, 636-645. https://doi.org/10.1176/appi.ajp.160.636

Gray, J. A., \& McNaughton, N. (2000). The Neuropsychology of Anxiety: An Enquiry into the Functions of the Septo-hippocampal System (Second Edition). Oxford University Press.

Gold, J. M., Barch, D. M., Carter, C. S., Dakin, S., Luck, S. J., MacDonald III, A. W., ... \& Strauss, M. (2012). Clinical, functional, and intertask correlations of measures developed by the Cognitive Neuroscience Test Reliability and Clinical Applications for Schizophrenia Consortium. Schizophrenia Bulletin, 38(1), 144-152.

Green, D. M., \& Swets, J. A. (1966). Signal Detection Theory and Psychophysics (Vol. 1). New York: Wiley.

Hahn, E., Gottschling, J., \& Spinath, F. M. (2012). Short measurements of personality - validity and reliability of the GSOEP Big Five Inventory (BFI-S). Journal of Research in Personality, 46, 355-359. http://dx.doi.org/10.1016/j.jrp.2012.03.008

Hasler, G., Drevets, W. C., Manji, H. K., \& Charney, D. S. (2004). Discovering endophenotypes for major depression. Neuropsychopharmacology, 29, 1765-1781. http://dx.doi.org/ 10.1038/sj.nnp.1300506

Hedge, C., Powell, G., \& Sumner, P. (2018). The reliability paradox: Why robust cognitive tasks do not produce reliable individual differences. Behavior Research Methods, 50(3), 1166-1186.

Hemphill, J. F. (2003). Interpreting the magnitudes of correlation coefficients. American Psychologist, $58,78-80$. 
Hyman, S. (2002). A new beginning for research on borderline personality disorder. Biological Psychiatry, 51, 933-935. http://dx.doi.org/10.1016/S006-3223(02)01408-7

Insel, T., Cuthbert, B., Garvey, M., Heinssen, R., Pine, D. S., Quinn, K., ... \& Wang, P. (2010). Research domain criteria (RDoC): toward a new classification framework for research on mental disorders. American Journal of Psychiatry, 167, 748-751.

John, O. P., Donahue, E. M., \& Kentle, R. L. (1991). The Big Five Inventory - Version 4a and 54. CA, Berkeley: University of California, Berkeley, Institute of Personality and Social Research.

Joiner, T. E., Brown, J. S., \& Metalsky, G. I. (2003). A test of the tripartite model's prediction of anhedonia's specificity to depression: Patients with major depression versus patients with schizophrenia. Psychiatry Research, 119, 243-250. http://dx.doi.org/10.1016/s01651781(03)00131-8

Kaiser, R. H., Treadway, M. T., Wooten, D. W., Kumar, P., Goer, F., Murray, L., ... \& Alpert, N. M. (2018). Frontostriatal and dopamine markers of individual differences in reinforcement learning: a multi-modal investigation. Cerebral Cortex, 28(12), 4281-4290.

Keedwell, P. A., Andrew, C., Williams, S. C., Brammer, M. J., \& Phillips, M. L. (2005). The neural correlates of anhedonia in major depressive disorder. Biological Psychiatry, 58(11), 843-853. http://dx.doi.org/10.1016/j.biopsych.2005.05.019

Kendall, P. C., Hollon, S. D., Beck, A. T., Hammen, C. L., \& Ingram, R. E. (1987). Issues and recommendations regarding use of Beck Depression Inventory. Cognitive Therapy and Research, 11, 289-299. http://dx.doi.org/10.1007/BF01186280

Kotov, R., Gamez, W., Schmidt, F., \& Watson, D. (2010). Linking “big” personality traits to anxiety, depressive, and substance use disorders: A meta-analysis. Psychological Bulletin, 136, 768. 
Kotov, R., Foti, D., Li, K., Bromet, E. J., Hajcak, G., \& Ruggero, C. J. (2016). Validating dimensions of psychosis symptomatology: Neural correlates and 20-year outcomes. Journal of Abnormal Psychology, 125(8), 1103.

Kotov, R., Krueger, R. F., Watson, D., Achenbach, T. M., Althoff, R. R., Bagby, R. M., ... Zimmerman, M. (2017). The Hierarchical Taxonomy of Psychopathology (HiTOP): A dimensional alternative to traditional nosologies. Journal of Abnormal Psychology, 126(4), 454477. http://dx.doi.org/10.1037/abn0000258

Krueger, R. F., Derringer, J., Markon, K. E., Watson, D., \& Skodol, A. E. (2012). Initial construction of a maladaptive personality trait model and inventory for DSM-5. Psychological Medicine, 42, 1879-1890. http://dx.doi.org/10.1017/S0033291711002674

Krueger, R. F., \& Markon, K. E. (2014). The role of the DSM-5 personality trait model in moving toward a quantitative and empirically based approach to classifying personality and psychopathology. Annual Review of Clinical Psychology, 10, 477-501. https://doi.org/10.1146/annurev-clinpsy-032813-153732

Kwapil, T. R., \& Barrantes-Vidal, N. (2015). Schizotypy: looking back and moving forward. Schizophrenia Bulletin, 41(suppl_2), S366-S373.

Lawlor, V. M., Webb, C. A., Wiecki, T. V., Frank, M. J., Trivedi, M., Pizzagalli, D. A., \& Dillon, D. G. (2019). Dissecting the impact of depression on decision-making. Psychological Medicine. https://doi.org/10.1017/S0033291719001570

Liu, W. H., Roiser, J. P., Wang, L. Z., Zhu, Y. H., Huang, J., Neumann, D. L., ... \& Chan, R. C. (2016). Anhedonia is associated with blunted reward sensitivity in first-degree relatives of patients with major depression. Journal of Affective Disorders, 190, 640-648. 
Loas, G. (1996). Vulnerability to depression: A model centered on anhedonia. Journal of Affective Disorders, 41, 39-53. https://doi.org/10.1016/0165-0327(96)00065-1

Lucas, R. E., Diener, E., Grob, A., Suh, E. M., \& Shao, L. (2000). Cross-cultural evidence for the fundamental features of Extraversion. Journal of Personality and Social Psychology, 79, 452. http://dx.doi.org/10.1037/0022-3514.79.3.452

MacCallum, R. C., Zhang, S., Preacher, K. J., \& Rucker, D. D. (2002). On the practice of dichotomization of quantitative variables. Psychological Methods, 7, 19-40. http://dx.doi.org/10.1037/1082-989X.7.1.19

Markon, K. E., Chmielewski, M., \& Miller, C. J. (2011). The reliability and validity of discrete and continuous measures of psychopathology: A quantitative review. Psychological Bulletin, 137(5), 856-879. http://dx.doi.org/10.1037/a0023678

McCarthy, D., \& Davison, M. (1979). Signal probability, reinforcement and signal detection. Journal of Experimental Analysis of Behavior, 32, 373-386. http://dx.doi.org/10.1901/jeab.1979.32-373

McDonald, R. P. (1999). Test theory: a unified treatment. Lawrence Earlbaum Associates. Inc., Mahwah, NJ, 142-145.

Meehl, P. E. (1975). Hedonic capacity: Some conjectures. Bulletin of the Menninger Clinic, 39, 295307.

Nosek, B. A., \& Smyth, F. L. (2007). A multitrait-multimethod validation of the implicit association test. Experimental Psychology, 54(1), 14-29.

Pinkham, A. E., Harvey, P. D., \& Penn, D. L. (2018). Social cognition psychometric evaluation: results of the final validation study. Schizophrenia Bulletin, 44(4), 737-748. 
Pizzagalli, D. A., Bogdan, R., Ratner, K. G., Jahn, A. L. (2007). Increased perceived stress is associated with blunted hedonic capacity: Potential implications for depression research. Behaviour Research and Therapy, 45, 2742-2753. http://dx.doi.org/10.1016/j.brat.2007.07.013

Pizzagalli, D. A., Goetz, E., Ostacher, M., Iosifescu, D. V., \& Perlis, R. H. (2008a). Euthymic patients with bipolar disorder show decreased reward learning in a probabilistic reward task. Biological Psychiatry, 64(2), 162-168.

Pizzagalli, D. A., Iosifescu, D., Hallett, L. A., Ratner, K. G., \& Fava, M. (2008b). Reduced hedonic capacity in major depressive disorder: Evidence from a probabilistic reward task. Journal of Psychiatric Research, 43, 76-87. http://dx.doi.org/10.1016/j.jpsychires.2008.03.001

Pizzagalli, D. A., Jahn, A. L., \& O’Shea, J. P. (2005). Toward an objective characterization of an anhedonic phenotype: A signal-detection approach. Biological Psychiatry, 57, 319-327. http://dx.doi.org/10.1016/j.biopsych.2004.11.026

Pizzagalli, D. A., Oakes, T. R., Fox, A. S., Chung, M. K., Larson, C. L., Abercrombie, H. C., Schaefer, S. M., Benca, R. M., Davidson, R. J. (2004). Functional but not structural subgenual prefrontal cortex abnormalities in melancholia. Molecular Psychiatry, 9, 393-405. http://dx.doi.org/10.1038/sj.mp.4001469

Revelle, W., \& Condon, D. M. (2019). Reliability from $\alpha$ to $\omega$ : A tutorial. Psychological Assessment, 31(12), 1395.

Richard, F. D., Bond Jr, C. F., \& Stokes-Zoota, J. J. (2003). One hundred years of social psychology quantitatively described. Review of General Psychology, 7(4), 331-363.

Robinson, M. D., Moeller, S. K., \& Ode, S. (2010). Extraversion and reward-related processing: Probing incentive motivation in affective priming tasks. Emotion, 10(5), 615-626. http://dx.doi.org/10.1037/a0019173 
Rueter, A. R., Abram, S. V., MacDonald III, A. W., Rustichini, A., \& DeYoung, C. G. (2018). The goal priority network as a neural substrate of Conscientiousness. Human Brain Mapping, https://doi.org/10.1002/hbm.24195

Rush, A. J., \& Weissenburger, J. E. (1994). Melancholic symptom features and DSM-IV. The American Journal of Psychiatry, 151, 489-498. http://dx.doi.org/10.1176/ajp.151.4.489

Santesso, D. L., Dillon, D. G., Birk, J. L., Holmes, A. J., Goetz, E., Bogdan, R., \& Pizzagalli, D. A. (2008). Individual differences in reinforcement learning: behavioral, electrophysiological, and neuroimaging correlates. Neuroimage, 42(2), 807-816.

Santesso, D. L., Evins, A. E., Frank, M. J., Schetter, E. C., Bogdan, R., \& Pizzagalli, D. A. (2009). Single dose of a dopamine agonist impairs reinforcement learning in humans: Evidence from event-related potentials and computational modeling of striatal-cortical function. Human Brain Mapping, 30(7), 1963-1976.

Schnabel, K., Asendorpf, J. B., \& Greenwald, A. G. (2008). Assessment of individual differences in implicit cognition: A review of IAT measures. European Journal of Psychological Assessment, 24(4), 210.

Schönbrodt, F. D., \& Perugini, M. (2013). At what sample size do correlations stabilize? Journal of Research in Personality, 74(5), 609-612. https://doi.org/10.1016/j.jrp.2013.05.009

Smillie, L. D. (2008). What is reinforcement sensitivity? Neuroscience paradigms for approachavoidance process theories of personality. European Journal of Personality, 22(5), 359-384.

Smillie, L. D. (2013). Extraversion and reward processing. Current Directions in Psychological Science, 22(3), 167-172. 
Smillie, L. D., Cooper, A. J., \& Pickering, A. D. (2011a). Individual differences in reward-predictionerror: extraversion and feedback-related negativity. Social Cognitive and Affective Neuroscience, 6(5), 646-652.

Smillie, L. D., Loxton, N. J., \& Avery, R. E. (2011b). Reinforcement Sensitivity Theory,Research, Applications and Future. In Chamorro-Premuzic, T., Furnham, A. F., \& von Stumm, S. (eds.) Handbook of Individual Differences. (pp. 101-131). Wiley-Blackwell.

Smillie, L. D., Cooper, A. J., Wilt, J., \& Revelle, W. (2012). Do extraverts get more bang for the buck? Refining the affective-reactivity hypothesis of Extraversion. Journal of Personality and Social Psychology, 103(2), 306-326. http://dx.doi.org/10.1037/a0028372

Smillie, L. D., Dalgleish, L. I., \& Jackson, C. J. (2007). Distinguishing between learning and motivation in behavioral tests of the reinforcement sensitivity theory of personality. Personality and Social Psychology Bulletin, 33(4), 476-489.

Smillie, L. D., \& Wacker, J. (2014). Dopaminergic foundations of personality and individual differences. Frontiers in Human Neuroscience, 8, article 874, https://doi.org/10.3389/fnhum.2014.00874

Snaith, P. (1993). Anhedonia: A neglected symptom of psychopathology. Psychological Medicine, 23, 957-966. http://dx.doi.org/10.1017/S0033291700026428

Stanislaw, H., \& Todorov, N. (1999). Calculation of signal detection theory measures. Behavior Research Methods, Instruments, \& Computers, 31(1), 137-149.

Tripp, G., \& Alsop, B. (1999). Sensitivity to reward frequency in boys with attention deficit hyperactivity disorder. Journal of Clinical and Child Psychology, 28, 366-375. http://dx.doi.org/10.1207.S15374424jecp280309 
Trivedi, M. H., McGrath, P. J., Fava, M., Parsey, R. V., Kurian, B. T., Phillips, M. L., ... \& Cooper, C. (2016). Establishing moderators and biosignatures of antidepressant response in clinical care (EMBARC): rationale and design. Journal of Psychiatric Research, 78, 11-23.

Vrieze, E., Pizzagalli, D. A., Demyttenaere, K., Hompes, T., Sienaert, P., de Boer, P., ... \& Claes, S. (2013). Reduced reward learning predicts outcome in major depressive disorder. Biological Psychiatry, 73(7), 639-645.

Webb, C. A., Dillon, D. G., Pechtel, P., Goer, F. K., Murray, L., Huys, Q. J., ... \& Kurian, B. T. (2016). Neural correlates of three promising endophenotypes of depression: evidence from the EMBARC study. Neuropsychopharmacology, 41(2), 454-463.

Webb, C. A., Trivedi, M. H., Cohen, Z. D., Dillon, D. G., Fournier, J. C., Goer, F., ... \& Adams, P. (2020). Personalized prediction of antidepressant v. placebo response: evidence from the EMBARC study. Psychological Medicine, 49(7), 1118-1127.

Whitton, A. E., Kakani, P., Foti, D., Van’t Veer, A., Haile, A., Crowley, D. J., \& Pizzagalli, D. A. (2016). Blunted neural responses to reward in remitted major depression: a high-density eventrelated potential study. Biological Psychiatry: Cognitive Neuroscience and Neuroimaging, 1(1), $87-95$.

Wittenborn, J. R. (1951). An evaluation of the use of difference scores in prediction. Journal of Clinical Psychology, 7, 108-111.

Widiger, T. A. (2011). Personality and psychopathology. World Psychiatry, 10, 103-106. http://dx.doi.org/10.1002/j.2051-5545.2011.tb00024.x

Wright, A. G. C., Krueger, R. F., Hobbs, M. J., Markon, K. E., Eaton, N. R., \& Slade, T. (2013). The structure of psychopathology: Toward an expanded quantitative empirical model. Journal of Abnormal Psychology, 122(1), 281-294. http://dx.doi.org/10.1037/a0030133 
Wright, A. G., Creswell, K. G., Flory, J. D., Muldoon, M. F., \& Manuck, S. B. (2019). Neurobiological Functioning and the Personality-Trait Hierarchy: Central Serotonergic Responsivity and the Stability Metatrait. Psychological Science, 30(10), 1413-1423. 


\section{Appendix}

Table A1. Pearson correlations of task performance with Extraversion and Neuroticism

\begin{tabular}{|c|c|c|c|c|c|c|c|c|c|c|c|c|c|c|c|c|c|c|c|}
\hline & 1. & 2. & 3. & 4. & 5. & 6. & 7. & 8. & 9. & 10. & 11. & 12. & 13. & 14. & $\mathrm{RB}$ & Accuracy & Discriminability & $\Delta \mathrm{RB} 1-2$ & $\Delta \mathrm{RB} 1-3$ \\
\hline 1. BFAS Extraversion & 1 & & & & & & & & & & & & & & .09 & -.03 & .00 & .06 & .08 \\
\hline 2. BFI Extraversion & .82 & 1 & & & & & & & & & & & & & .11 & -.07 & -.07 & .12 & .09 \\
\hline 3. BFAS Extraversion - Peer & .62 & .62 & 1 & & & & & & & & & & & & .06 & .10 & .11 & .16 & .08 \\
\hline 4. BFI Extraversion - Peer & .58 & .69 & .83 & 1 & & & & & & & & & & & .11 & .00 & .03 & .19 & .11 \\
\hline 5. BFAS Neuroticism & -.39 & -.30 & -.20 & -.17 & 1 & & & & & & & & & & .02 & -.07 & -.05 & .01 & -.06 \\
\hline 6. BFI Neuroticism & -.37 & -.31 & -.22 & -.19 & .81 & 1 & & & & & & & & & .02 & -.05 & -.05 & -.01 & -.03 \\
\hline 7. BFAS Neuroticism - Peer & -.19 & -.13 & -.34 & -.26 & .55 & .57 & 1 & & & & & & & & .10 & -.13 & -.12 & .02 & .03 \\
\hline 8. BFI Neuroticism - Peer & -.26 & -.24 & -.39 & -.33 & .55 & .63 & .91 & 1 & & & & & & & .03 & -.09 & -.10 & -.04 & -.04 \\
\hline 9. BDI & -.22 & -.24 & -.25 & -.16 & .47 & .47 & .29 & .35 & 1 & & & & & & -.07 & -.08 & -.08 & -.07 & -.12 \\
\hline 10. PID-5 Depressivity & -.44 & -.37 & -.33 & -.20 & .59 & .63 & .37 & .40 & .59 & 1 & & & & & -.05 & -.06 & -.06 & -.05 & -.13 \\
\hline 11. PID-5 Anhedonia & -.59 & -.53 & -.45 & -.35 & .53 & .52 & .38 & .41 & .45 & .73 & 1 & & & & -.07 & -.06 & -.06 & -.02 & -.05 \\
\hline 12. RB Block 1 & .00 & -.02 & -.08 & -.08 & .11 & .12 & .09 & .09 & -.03 & .00 & -.01 & 1 & & & & -.10 & -.07 & -.54 & -.52 \\
\hline 13. RB Block 2 & .07 & .10 & .09 & .12 & .13 & .11 & .11 & .04 & -.02 & -.02 & -.03 & .41 & 1 & & & .01 & .14 & .55 & .09 \\
\hline 14. RB Block 3 & .08 & .03 & .00 & .04 & .04 & .07 & .11 & .03 & -.05 & -.10 & -.08 & .30 & .48 & 1 & & -.18 & -.07 & .13 & .65 \\
\hline Mean & 3.69 & 3.30 & 3.75 & 3.56 & 2.59 & 2.56 & 2.61 & 2.63 & 12 & 1.43 & 1.65 & .13 & .18 & .20 & .19 & .79 & .65 & .18 & .20 \\
\hline SD & .57 & .82 & .47 & .68 & .67 & .78 & .61 & .71 & 8.08 & .50 & .54 & .19 & .19 & .21 & .17 & .09 & .27 & .19 & .21 \\
\hline
\end{tabular}

Notes. $N=299$ (236 for peer-report measures). Correlations of $r>.11$ are significant (at an $\alpha$ of .05) for all variable pairs not

including peer reports, and variable pairs including peer reports are significant when $r>.12 . \mathrm{BFAS}=$ Big Five Aspect Scales,

BFI = Big Five Inventory, BDI = Beck Depression Inventory, PID-5 = Personality Inventory for DSM-5, RB = response bias,

$\Delta \mathrm{RB}=$ change in response bias. 
Figure A1. Model of Extraversion, Neuroticism, and response bias (without depression)

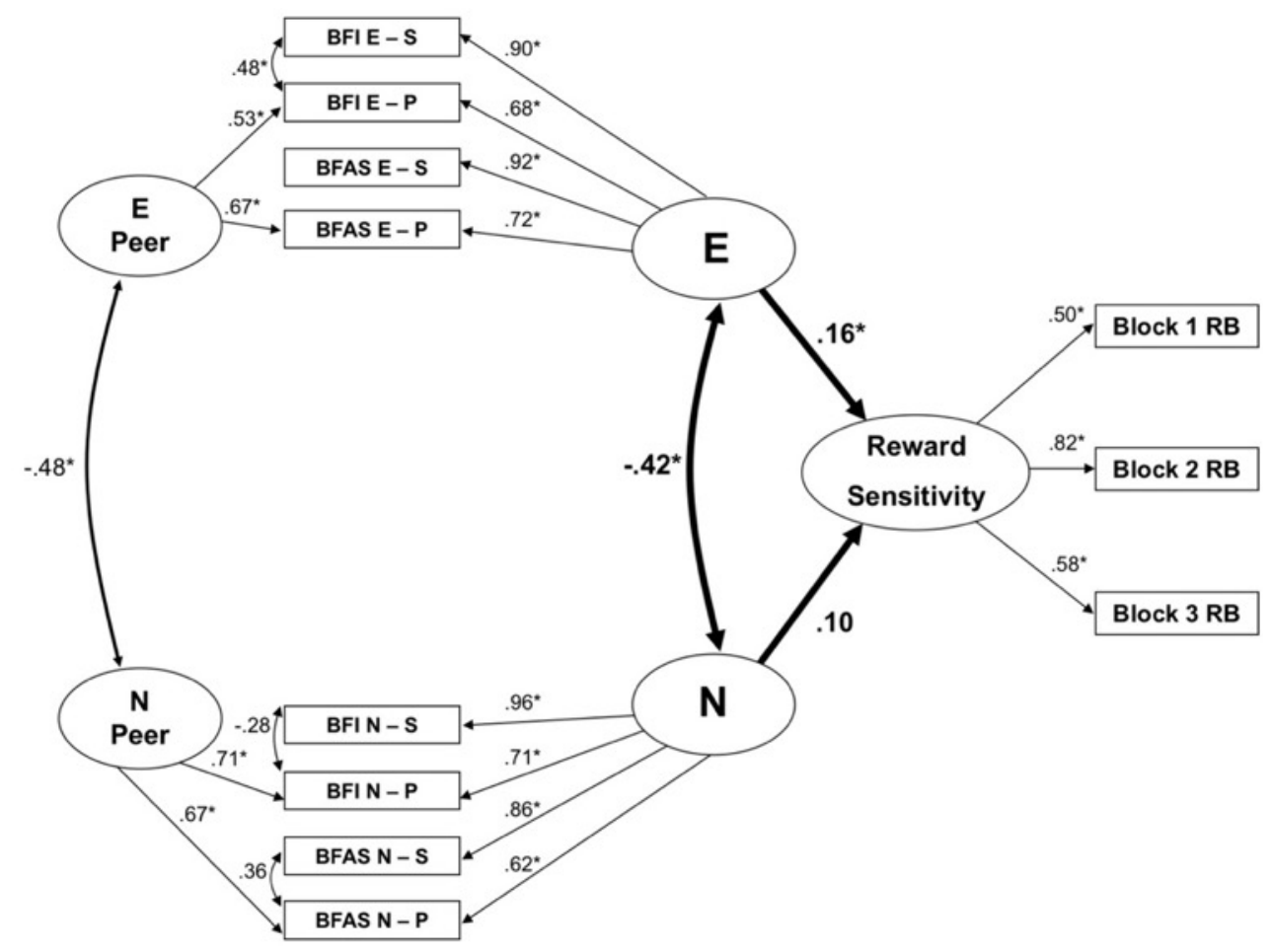

Figure A2. Model of Extraversion, Neuroticism, and response bias controlling for baseline (without depression)

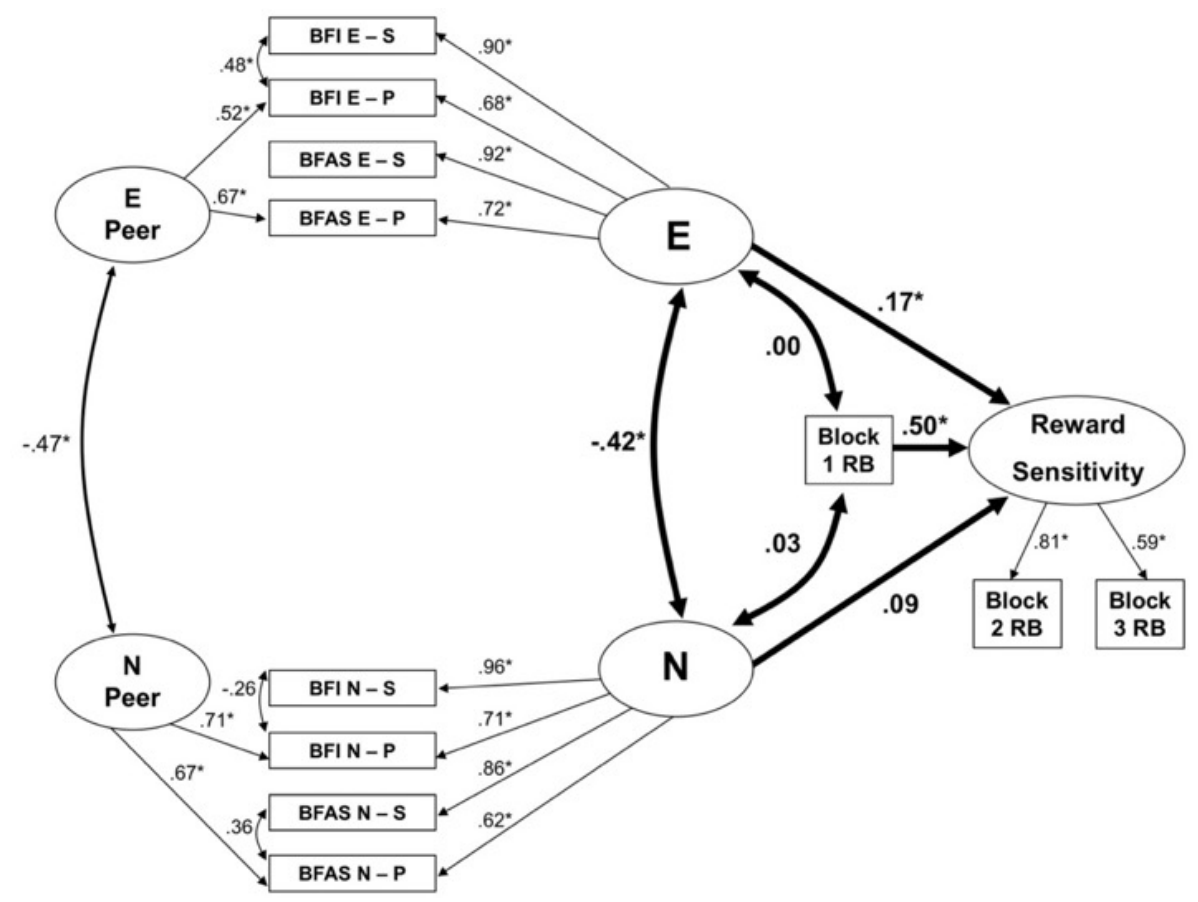

